Research Article/Araştırma Makalesi

\title{
Design, Development and Evaluation of New Generation Learning Objects for Vocational Education
}

\author{
G. Alev ÖZKÖK* 1 (D) Tuğçe YILMAZ 2 (iD \\ ${ }^{1}$ Hacettepe University, Faculty of Education, Ankara, Turkey, ozkok@hacettepe.edu.tr \\ ${ }^{2}$ TÜBITTAK BILLGEM, Ankara, Turkey, tugce.yilmaz@tubitak.gov.tr \\ * Corresponding Author: ozkok@hacettepe.edu.tr
}

\begin{tabular}{|c|c|}
\hline Article Info & Abstract \\
\hline $\begin{array}{l}\text { Keywords: Learning object, design } \\
\text { based research model, vocational } \\
\text { education } \\
\text { doi } 10.18009 / \text { jcer. } 770034 \\
\text { Publication Language: Turkish }\end{array}$ & $\begin{array}{l}\text { In this study, it is aimed to model the development process of the new } \\
\text { generation learning object for vocational education students. The } \\
\text { research, which was designed with a synthesized design-based } \\
\text { research method, was carried out in two meso cycles. The sequentially } \\
\text { structured development process in the first cycle was rearranged in a } \\
\text { spiral structure in the second cycle. Implementation process was } \\
\text { carried out in collaboration with Information Technology and } \\
\text { Mathematics teachers. } 25 \text { 11th grade students without coding } \\
\text { experience participated in the research during the Fall and Spring } \\
\text { semesters of } 2018-2019 \text { academic year. During the development } \\
\text { process, the students' perception of quality towards the learning object } \\
\text { was evaluated with the Learning Object Quality Rubric and student } \\
\text { interview form. It is believed that the research differs from the relevant } \\
\text { studies in the literature since it provides a comprehensive process } \\
\text { model for contributing to the quality levels of the new generation } \\
\text { learning object development process. }\end{array}$ \\
\hline CrossMark CC & $\begin{array}{l}\text { To cite this article: Özkök, G.A., \& Yılmaz, T. (2020). Mesleki } \\
\text { eğitime yönelik yeni nesil öğrenme nesnelerinin tasarlanmas1, } \\
\text { geliştirilmesi ve değerlendirilmesi. Journal of Computer and Education } \\
\text { Research, } 8(16), 757-786 \text {. DOI: } 10.18009 \text { jcer.770034 }\end{array}$ \\
\hline
\end{tabular}

\section{Mesleki Eğitime Yönelik Yeni Nesil Öğrenme Nesnelerinin Tasarlanması, Geliştirilmesi ve Değerlendirilmesi}

\begin{tabular}{|c|c|}
\hline Makale Bilgisi & $\ddot{\mathrm{O} z}$ \\
\hline 15 Tеттиz 2020 & $\begin{array}{l}\text { Bu araştırmada mesleki eğitim öğrencileri için yeni nesil öğrenme } \\
\text { nesnesi geliştirme sürecinin modellenmesi amaçlanmıştır. Sentezlenmiş }\end{array}$ \\
\hline 29 Eylül 2020 & $\begin{array}{l}\text { tasarım-tabanlı araştırma yöntemiyle desenlenen araştırma, iki mezo } \\
\text { döngüde gerçekleştirilmiştir. Birinci döngüde sıralı yapılandırılan } \\
\text { geliştirme süreci, ikinci döngüde sarmal yapıda yeniden }\end{array}$ \\
\hline $\begin{array}{l}\text { Anahtar kelimeler: } \quad \text { Öğrenme } \\
\text { nesnesi, tasarım tabanlı araştırma } \\
\text { modeli, mesleki eğitim }\end{array}$ & $\begin{array}{l}\text { düzenlenmiştir. Uygulama, Bilişim Teknolojileri ve Matematik } \\
\text { öğretmenleriyle işbirliği içerisinde yapılmıştır. Araştırmaya 2018-2019 } \\
\text { öğretim yılı Güz ve Bahar dönemlerinde, kodlama deneyimi olmayan } \\
25 \text { 11. sınıf öğrencisi katılmıştır. Geliştirme sürecinde öğrencilerin }\end{array}$ \\
\hline doi) $10.18009 /$ jcer.770034 & $\begin{array}{l}\text { öğrenme nesnesine yönelik kalite algı düzeyleri, Öğrenme Nesnesi } \\
\text { Kalite Rubriği ve öğrenci görüşme formu ile değerlendirilmiştir. }\end{array}$ \\
\hline Yayım Dili: Türkçe & $\begin{array}{l}\text { Araştırmanın, yeni nesil öğrenme nesnesi geliştirme sürecinin kalite } \\
\text { düzeylerine katkı sağlamasına yönelik kapsamlı bir süreç modeli } \\
\text { sunuyor olması nedeniyle alanyazındaki ilgili araştırmalardan ayrıldığı } \\
\text { düşünülmektedir. }\end{array}$ \\
\hline
\end{tabular}




\title{
Summary
}

\section{Design, Development and Evaluation of New Generation Learning Objects for Vocational Education}

\begin{abstract}
Introduction
Since the 2000s, there has been a significant increase in the use of digital learning contents, referred to as "learning objects", in order to increase the effectiveness and efficiency of various teaching strategies within the scope of e-learning. In the process of Information and Communications Technologies (ICT), namely the technological evolution, providing an end-to-end IP access extending from $1 \mathrm{G}$ to $4 \mathrm{G}$ and even 5G through the inclusion of smart mobile devices, the concept of ICT4D (Information and Communications Technologies for Development) has constituted the infrastructure of contemporary technology. Analyzing the rapid transformation of technology on a sectoral basis, education has been regarded amongst those areas extensively transferring innovation. On account of the rapid development of ICT in education, it has been observed that there have been praiseworthy efforts of countless institutes and researchers in utilizing the recent technology for the discovery of solutions to the related problems in the area. As a benchmark of development, the high potential of the skills of using ICT has been necessarily suggested as a creator of a more developed society on its own or a highly qualified workforce which has been globally required.

Recently, the studies on the use of ICT in educational area has seemly moved towards ICT for Development (ICT4D). In other words, ICT offers “development" opportunities in addition to the efficiency of ICT usage it provides, and plays a role in predicting development opportunities parallel to the global technological development process of societies. ICT for development also shows itself in the field of e-learning. Digital learning objects, one of the most important developments within the scope of ICT in e-learning, were also affected by this change process. The digital learning object, opposing the traditional understanding of teaching in accordance with learning outcomes specified by the conceptual framework, is based on the instructional design technology, a new type of computer-based teaching that draws on the object-oriented paradigm of computer science.
\end{abstract}


Since the 2000s, there has been a significant increase in the use of digital learning contents, referred to as "learning objects", in order to increase the effectiveness and efficiency of various teaching strategies within the scope of e-learning. Baki and Çakıroğlu (2010) stated that the inclusion of learning objects in the educational process had led to redefinition of the teaching styles of the educators and the learning styles of the learners. Learning objects emerged as a key strategy for the creation, sharing and convenient dissemination of learning resources in the 1990s (Gordillo, Barra, \& Quemada, 2017; Wiley, 2000). These objects can be used repeatedly in alternative contexts to scaffold specific learning objectives (Becerra, Astudillo, \& Mendoza, 2012). In the literature of e-learning, it is stated in the studies that learning object researches form an independent and extensive title (örn. Burbaitė, Bespalova, Damasevicius, \& Stuikys, 2014; Northrup, 2007; Štuikys, Burbaite, \& Damaševicius, 2013; Wang, Mendori, \& Hoel, 2019). Learning object has been widely used as an alternative method to support a particular learning outcome in the process of contemporary education and teaching (Becerra vd., 2012).

Within the scope of the study, it has been aimed to design, develop and evaluate the new generation learning object, which is formed in a hypothetical structure within the perceptions of information quality, content quality and technical quality of the students of vocational education, considering the criteria of complex pedagogical, content and technical quality.

\section{Research Problem}

How should the process of developing a new generation learning object for high school students be modeled according to the learning object quality criteria?

\section{Sub Problems}

- To what extend is the degree of the new generation learning object in terms of students' pedagogical quality, content quality, and technical quality perceptions?

- What are the views of students on the new generation learning object development process?

\section{Method}

This research was designed based on the synthesized design based research model developed by Van Wyk and De Villiers (2014) on the basis of the principles of the design based research method (McKenney \& Reeves, 2012). The research consists of two meso cycles and the micro cycles of "problem analysis", "solution design", "solution development", 
"evaluation in practice" and "reflection". The research was conducted with the participation of 25 students in the 11th grade studying Information Technologies in a vocational high school in Ankara. During 2018 - 2019 Fall Term the first, and in the Spring Term the second meso cycle was carried out.

\section{Results, Discussion and Conclusions}

In this research, a new generation learning object (NGLO), considering the pedagogical, content and technical quality perceptions of the students, has been evaluated in terms of design and development. The research has been designed on the basis of a synthesized design based research model in two consecutive cycles with the 11th grade students of Information Technologies in vocational education. It has been aimed with the modeling in this study to design, develop and evaluate the process of formation of NGLO. The process is designed within the scope of the criteria of pedagogical quality, content quality and technical quality criteria along with the sub-criteria of problem solving. The NGLO developed to be applied in learning and teaching process has been structured within the scope of design, development and evaluation drawing on the criteria of (a) learning scope, (b) learning outcome, (c) interaction level, (d) modularity of content, (d) perceived learning, (e) time of response, (f) convenience of access, (g) sense of control, (h) assistance, (i) feedback, (i) documenting of record (j) timeliness, (k) understandability, (l) relevance, (m) accordance, (n) content sequence, (o) content design.

Within the scope of this study, NGLO, designed on the basis of pedagogical quality, content quality and technical quality criteria, has been developed. In addition, the NGLO has been designed, developed and evaluated. The process of developing a new generation learning object in learning and teaching could be examined in the upcoming research, drawing on cognitive load theory and its effect within the educational context. 


\section{Giriş}

Bilgi ve İletişim Teknolojileri (BİT) olarak adlandırılan 1G'den başlayarak uçtan uca IP erişimi sağlayan akıllı mobil cihazların hayatımıza dâhil olduğu teknolojik evrim olarak nitelendirilen 4G, hatta 5G'ye uzanan süreçte, Gelişimde BİT (ICT4D-Information and Communications Technologies for Development) kavramı, günümüz teknolojinin alt yapısını oluşturmaktadır. Teknolojinin hızlı dönüşümü sektörel bazda incelendiğinde, yenilikleri en çok transfer eden alanlardan birisinin de eğitim alanı olduğu görülmektedir. Eğitim alanında BİT’nin hızlı gelişimi, bu teknolojileri eğitim alanı ile ilgili sorunların çözümüne nasıl yönlendirilebileceği konusunda birçok kurum ve araştırmacının takdire şayan çabaları gözlenmektedir. Gelişim ölçütü olarak BİT kullanım becerilerinin potansiyelinin yüksek olması, BİT'nin kullanımının kendi başına daha gelişmiş bir toplum veya küresel anlamda toplumun ihtiyacı olan yüksek nitelikli işgücü yarattığına yorulmamalıdır.

Son yıllarda eğitim alanında BİT'nin kullanımına dönük çalışmalar, Gelişimde BİT'e (ICT4D) doğru bir dönüşüm sürecine girmiştir. Diğer bir deyişle Gelişimde BİT, sağladığı BİT kullanım verimliliği yanında "gelişim" fırsatları sunmakta, toplumların küresel bazdaki teknoloji geliştirme sürecine paralel gelişim fırsatlarının öngörülmesinde rol oynamaktadır. Gelişimde BİT, e-öğrenme alanında da kendisini göstermektedir. BİT’nin e-öğrenme kapsamında en önemli gelişmelerden biri olan dijital öğrenme nesneleri de bu değişim sürecinden etkilenmiştir. Kavramsal çerçevesi belirlenmiş öğrenme kazanımlarına göre kurgulanan geleneksel öğretim anlayışı ile çelişen dijital öğrenme nesnesi, bilgisayar biliminin nesne temelli paradigmasına dayanan bilgisayar temelli öğretimin yeni bir türü olan öğretim tasarımı teknolojisine dayanmaktadır.

2000'li yıllardan bu yana e-öğrenme kapsamında öğretim tasarımındaki çeşitli öğretim stratejilerinin etkinliğini ve verimliliğini arttırmak amacıyla öğrenme nesneleri diye ifade edilen dijital öğrenme içeriklerinin kullanımında ciddi bir artış gözlenmektedir. Baki ve Çakıroğlu (2010), Öğrenme nesnelerinin eğitim-öğretim sürecine dâhil edilmesinin eğitimcilerin öğretme biçimlerinin ve öğrenen kişilerin öğrenme şekillerinin yeniden tanımlanmasına yol açtığını ifade etmişlerdir. Öğrenme nesnesi 1990’lı yıllarda öğrenme kaynaklarının oluşturulması, paylaşılması ve kolay yayılımı için anahtar bir strateji olarak ortaya çıkmıştır (Gordillo, Barra, \& Quemada, 2017; Wiley, 2000). Bu nesneler, belirli öğrenme hedeflerini desteklemek için alternatif bağlamlarda tekrar tekrar 
kullanılabilmektedir (Becerra, Astudillo, \& Mendoza, 2012). E-öğrenme alanyazınında öğrenme nesnesi araştırmalarının bağımsız ve geniş bir konu başlığı oluşturduğu araştırmalarda ifade edilmektedir (örn. Burbaitė, Bespalova, Damasevicius, \& Stuikys, 2014; Northrup, 2007; Štuikys, Burbaite, \& Damaševicius, 2013; Wang, Mendori, \& Hoel, 2019). Öğrenme nesneleri günümüz eğitim-öğretim sürecinde belirli bir öğrenme kazanımını desteklemek için alternatif bir yöntem olarak yaygın olarak kullanılmaktadır (Becerra vd., 2012).

Öğrenme nesnesi, bir metnin paragrafı gibi anlamlı en küçük öğretim materyalinden, bir öğretim tekniğindeki bütün ders programı gibi belirli disipline ait öğretim programının tümünü kapsayan çok büyük kaynaklara kadar jenerik anlamları kapsayan bir kavramdır (Barritt \& Alderman Jr., 2004; Queiros, da Silveria, da Silva Correia-Neto, \& Vilar, 2016). Öğrenme nesnelerinin, farklı formattaki görsel ve sözsel çoklu ortam materyallerini bütünleştirmeleri ve anlık geri bildirim sağlamaları nedeniyle kullanımı kolay ve ilgi çekici oldukları söylenebilir (Barak \& Ziv, 2013). Öğrenme nesneleri üzerine yapılan araştırmalar, geleneksel öğretim materyallerinin kullanımına kıyasla, öğretim esnasında öğrenme nesnelerinin öğrencilerin içerikle daha fazla ilgili olmalarını sağladığını ve performanslarını arttırdığını göstermektedir (Kay \& Knaack, 2008).

Milli Eğitim Bakanlığı 2023 Eğitim Vizyonu Raporu'na (MEB, 2018) göre, “Öğrenme Süreçlerinde Dijital İçerik ve Beceri Destekli Dönüşüm” çerçevesi altında belirlenen hedefler doğrultusunda dijital öğrenme içerikleri; pedagojik olarak desteklenmiş, içeriği bir bütünü yansıtan, kavramsal öğrenmeye önem veren, gerçek yaşam ile bağlantılı etkileşimi yüksek materyaller olarak adlandırılmaktadır. Dijital içeriklerin etkili kullanımı ile öğrencilerin motivasyonlarının desteklenmesi, günlük yaşam ile bağlantılı ölçme değerlendirme yaklaşımlarının getirilmesi, öğrencilerin bilgiye ihtiyaç duyma farkındalığının kazanması bu kapsamda tüm öğrencilere fırsat eşitliğinin sağlanması hedeflenmektedir (MEB, 2018).

Günümüzde yeni nesil öğrenme ortamları için geliştirilen akıllı öğrenme nesnesi yaklaşımları; (a) Öğrencilere daha iyi geri bildirim vermek için geliştirilen akıllı arayüz entegre öğrenme nesneleri (Silveira \& da Silva, 2008), (b) öğrenme nesnelerinin kişiselleştirilmesi için semantik web (Web 3.0) uygulaması (Kurilovas, Kubilinskiene, \& Dagiene, 2014), (c) öğrenme nesnelerinin meta verilerinin otomatik olarak oluşturulmasını sağlayan mimari (Li \& Li, 2014), (ç) bileşenleri arasında semantik bağlantı yapılandırılmış aktif öğrenme nesneleri (Slotkienè, Baniulis, \& Paulikas, 2009), (d) karmaşık öğrenme 
senaryoları tasarlamak ve öğrencinin öğrenme deneyimini takip etmek için e-öğrenme standartları ve akıllı nesneleri birleştiren mimari (Taamallah \& Khemaja, 2014), (e) kullanıcının gereksinimlerine göre öğrenme içeriğini otomatik olarak üretmek ve uyarlamak için meta-programlama kullanan bir üst seviye tanımlama olarak adlandırılan akıllı öğrenme nesneleri (Štuikys, 2015) şeklinde sıralanabilir.

Öğrenme nesnelerinin geliştirme sürecinde net bir şekilde tanımlanmış ve yaygın olarak benimsenmiş öğrenme nesnesi özellikleri ve geliştirme yöntemleri bulunmamaktadır (Štuikys, 2015). Öğrenme nesneleri dikkatli bir şekilde yapılandırıldıklarında, ardışık kullanıldıklarında ve iyi yönetildiklerinde, potansiyel olarak daha gelişmiş kaliteli eğitimin ortaya çıkmasına yol açarak, büyük bir makinedeki çark dişlisi gibi işlev görebilme potansiyeline sahiptir. Öğrenme nesnesi, paydaşların eğitim ihtiyaçlarını destekleyen öğrenme deneyimleri oluşturmak ve sunmak için kullanılan bir yapı olarak ele alınmaktadır. Öğrenme nesnesi, “kaliteli eğitim” sağlayan mekanizmalar olarak görülmektedir (Ritzhaupt, 2010).

Öğrenme nesnelerinin geliştirilmesi sürecinde, içeriğe ve bu içeriğin paketlenmesi ve tanımlanmasına yönelik standartlar tanımlanmıştır (ADL 2004; Boyle, 2009; IEEE, 2002; IMS, 2004). Öğrenme nesnelerini oluşturma sürecinde ne pedagoji, ne içerik, ne de teknik özellikler açısından yüksek kaliteli öğrenme nesnelerinin nasıl tasarlanıp geliştirileceğine dair belirlenmiş yönergeler bulunmamaktadır. Öğrenme nesneleri geliştirme sürecine ilişkin mevcut araştırmalar, pedagojik, içerik ve teknik açıdan bütüncül yetersizliklere vurgu yapmaktadır (Di Nitto, Mainetti, Monga, Sbattella, \& Tedesco, 2006; Mavrommatis, 2008).

Bu bağlamda bu çalışmanın amacı, ortaöğretim düzeyinde öğrencilerin bilgi kalitesi, içerik kalitesi ve teknik kalite algılarına göre hipotetik yapıda yapılandırılan yeni nesil öğrenme nesnesini (YNÖN) karmaşık pedagojik, içerik ve teknik kalite ölçütlerine göre tasarlamak, geliştirilmek ve değerlendirmektir.

\section{Öğrenme Nesnesi}

Öğrenme nesneleri, öğrenenler tarafından yönetilebilen, etkileşimli ve üzerinden uygun dönütler ve pekiştireçler verilebilen bilgi yığınlarının oluşturduğu öğrenme birim kümeleridir. Birim kümelerinin oluşturduğu öğrenme nesnelerinin pedagojik, içerik ve teknik niteliği arttırıldığında, öğrenenin dikkati ve motivasyonu artar (Lau \& Woods, 2009b). Pedagojik, içerik ve teknik olarak nitelikli bir öğrenme nesnesinde, öğrenenin küçük birimlerinin üzerinde düşünmesi ve öğrenmenin kendi bilgi yapısı içerisinde oluşturulması, 
büyük öğrenme birimlerine kıyasla nispeten daha kolay olacağı için küçük ve ayrı öğrenme nesneleri pedagojik açıdan daha uygundur.

Öğrenme nesneleri gerçek hayatta tasviri zor ya da imkânsız olan karmaşık kavramların sunumunda dijital benzetimler şeklinde kullanılabilir (Chapuis, 2003). Öğrenme nesnelerinin en iyi uygulamalarının nasıl olacağına işaret eden pedagojik, içerik ve teknik niteliğini belirleyen standartları tarif eden modellerin bulunmaması bu anlamda bir zorluk olmuştur. Mcgee (2003) e-öğrenme ortamlarında, öğrenme nesnelerinin tasarımı ve öğrenme modellerini irdelemiştir. Öğrenme nesnelerinin farklı e-öğrenme ortamlarında karşılanması zor olan öğrenme ihtiyaçlarını karşılaması için birtakım özel niteliklere sahip olması gerekir.

1992 yılında, Hodgins öğrenme stratejileriyle ilgili bazı sorunlarla uğraştı̆̆ı esnada, çocuklarından birinin Lego blokları oynamasını izlerken “Öğrenme Nesnesi” fikri doğmuştur. Hodgins, endüstrinin gereksinim duyduğu birlikte çalışabilir "tak ve kullan" modüler birimlerin, öğrenme sürecinde yeniden uyarlanabilir öğrenme bileşenleri ile ilişkisini fark etmiştir. Bu yeniden düzenlenebilen farklı boyuttaki ve türdeki modüler birimleri "öğrenme nesneleri” olarak adlandırmıştır (Saum, 2007). Hodgins (2002) öğrenme nesnelerini, münferit olarak öğrencinin ilgi alanına ve ihtiyaçlarına cevap verecek şekilde, meta veriler ile etiketlenerek bir araya getirilmesiyle oluşturulmuş bilgi nesneleri koleksiyonu olarak tanımlamıştır. Bilgi nesnesi, sayısal bilgi parçası, öğrenme materyali, öğretim nesnesi, sayısal kaynak, e-öğrenme kaynağı, öğrenme birimi, içerik birimi, etkileşimli nesne gibi farklı şekillerde adlandırılan öğrenme nesnesi kavramı çok sayıda farklı şekillerde tanımlanmıştır (Özkök, 2015). Öğrenme nesneleri ayrık, tekrar kullanılabilir ve bağlamdan bağlamsız bir öğrenme parçasıdır (Baruque \& Melo, 2004). Öğrenmeyi desteklemek için tekrar kullanılabilme özelliğine sahip herhangi bir dijital kaynaktır (Wiley, 2000). Tekrar kullanılabilme özelliğine sahip veya referans olabilecek dijital veya dijital olmayan herhangi bir varlıktır (IEEE, 2002). İçerik parçalarının, uygulama parçalarının ve değerlendirme unsurlarının tekil bir odak temelinde birleştirilmesidir (Polsani, 2003). Öğrencilerin bilişsel süreçlerini geliştirerek, güçlendirerek ve yönlendirerek belirli kavramların öğrenilmesini destekleyen, tekrar kullanılabilir ve interaktif web tabanlı araçlardır (Kay \& Knaack, 2008). Bir veya daha fazla öğretim hedefini veya kavramını öğretmeyi amaçlayan bağımsız, tekrar kullanılabilir, dijital bir kaynaktır (Mavrommatis, 2008). 
Bir öğrenme nesnesinin, tekrar kullanılabilmesi maksadıyla; modüler, keşfedilebilir ve birlikte çalışabilir olması gerekir (Friesen, 2001). Bu özellikleri sağlayabilmek ve öğrenme nesnelerinin verimliliğini, etkinliğini ve tekrar kullanılabilirliğini geliştirmek için çok sayıda araştırmacı büyük çaba harcamıştır. Öğrenme nesneleri, erişilebilir, yani ağ üzerinden kolayca ulaşılabilir; birlikte çalışabilir, platformlar ve bilişim araçları ile uyumlu olmalıdır. Zamana dayanıklı, farklı bağlamlarda tekrar kullanılabilir; uygun fiyatlı, zaman ve maliyet optimizasyonu açısından makul olmalıdır. Öğrenme nesnesi kendisini oluşturan unsurların istikrarlı olacağı ve hedeflenen amaçlara ve istenen öğrenme deneyimine ulaşılmasına yol açacak şekilde yapılandırılmalıdır.

\section{Öğrenme Nesneleri Kalite Ölçütleri}

Genel olarak, iyi bir öğrenme kaynağı, amaca uygun, kullanıcıların ihtiyaçlarını karşılayan ve aynı zamanda hedeflenen kullanıcılara bilgi sunma imkânını sekteye uğratabilecek teknik sorunları da çözebilen bir yapıya sahiptir. Öğrenme nesnelerinin geliştirilmesine yönelik geleneksel yaklaşım, içeriğe ve bu içeriğin paketlenmesi ve tanımlanmasına yönelik standartlara (ADL SCORM, 2004; IEEE, 2002; IMS, 2009) odaklanmıştır (Boyle, 2009). Geleneksel ve standart temelli yaklaşımda ne pedagojik kalite ne de tekrar kullanımı kolaylaştıracak içerik kalitesi ve teknik kalite açısından yüksek kaliteli öğrenme nesnelerinin nasıl geliştirileceğine dair standart ölçütler içeren yönerge bulunmamaktadır. Öğrenme nesneleri geleneksel yaklaşımında, tekrar kullanılabilirlik özelliği açısından pedagojik olarak oldukça sınırlı ve büyük ölçüde içeriğe odaklanmıştır (IEEE, 2002; Boyle, 2009).

Lau ve Woods (2009a), öğrenme nesnesi ile ilgili alanyazın taraması sonucunda hangi pedagojik, içerik ve teknik kriterlere göre geliştirilmesi gerektiği sorusunun pek çok araştırmacının ilgilendiği bir başlık olmadığını belirtmiştir. Çok sayıda e-öğrenme ortamı ve e-öğrenme içeriği araştırmacısı, bu sorunların üstesinden gelmek için çeşitli öğretim tasarımı stratejileri denemiştir.

Pedagojik kalite; öğrenme nesnelerinin öğrenenlerin öğrenme ihtiyaçlarına ne kadar iyi uyarlandığı ile alakalı bir kavramdır. Belirli bir ders aktivitesi için öğrenme yaklaşımı, açık, tam ve yeterli derinlikte olmalıdır. Öğretme ve öğrenme aracı olarak öğrenme nesnelerinin potansiyel etkililiği, ulaşılmak istenen öğrenme kazanımını desteklemek amacıyla kullanılacak içeriğe uygun olması ile ilişkilidir. Ayrıca pedagojik kalite, öğrenme nesnelerinin bir öğretme ve öğrenme aracı olarak potansiyel etkinliğinin, ulaşılması beklenen 
öğrenme hedefini desteklemek için kullanılacağı bağlamlarla uyuşup uyuşmadığı hususuyla da ilişkilidir (Lau \& Woods, 2008; 2009a). Öğrenme hedeflerine ulaşmak için öğrenme nesnesinde bulunması gereken öğretimsel yapı olarak da değerlendirilmektedir. Pedagojik kalite boyutu, öğrenme nesnesinde bulunması zorunlu bir gereklilik olan öğretimsel yönü, öğrenme hedeflerine ulaşmada öğrenme-öğretme süreci bakımından değerlendirme imkanı sunmaktadir.

Öğrenme nesnelerinin sadece pedagojik boyutlarını ele alan araştırmalar incelendiğinde,

(a) her öğrencinin kendi baskın öğrenme stiline uygun olan öğrenme nesneleri ile öğrenme durumlarının öğrenme nesnesi geliştirme aşamalarına entegre edildiği, (Saldana Hernandez, Hernández Velázquez, López Domínguez, Excelente Toledo, \& Medina Nieto, (2018; Wang vd., 2019),

(b) öğrenme kuramlarına dayalı olarak öğrenme nesnelerinin tasarlanma, geliştirilme ve değerlendirme süreçlerinin yürütüldüğ̈̈ (Wang vd., 2019),

(c) öğrenci öğrenmesinde motivasyon faktörünün ele alındığ (Wang vd., 2019),

(d) öğrencilerin derse karşı tutumları ve başarı durumlarının değerlendirildiği (Wang vd., 2019) örnek olarak gösterilebilir.

İçerik kalitesi; öğrenenin öğrenme ihtiyaçlarına ne kadar iyi uyarlandığ $\breve{1}_{1}$ ile alakalı bir kavramdır. Belirli bir ders aktivitesi için öğrenme nesnesinin içerik hacminin doğru bilgi içermesi gerekmektedir. Ayrıca, içerik kalitesi, öğrenme nesnesinin içerik kapsamının öğrencilerin öğrenme hedeflerine ne kadar iyi uyum sağladığı ile de ilgilidir. Öğrenme nesnesinin içeriğinin potansiyel etkililiği, belirli bir öğretim programının doğru, eksiksiz ve yeterli içeriğe sahip olması olarak anlaşılabilir (Lau \& Woods, 2008). E-öğrenme ortamlarında, öğrenenlerin öğrenme hedeflerine ulaşmaları için öğrenme nesnelerinin, kapsamlı, güncel ve doğru bilgi ile yapılandırılmış kolay anlaşılır içeriği, öğrencilerin öğrenmeye karşı istekli olmalarını sağlayacaktır (Lau ve Woods, 2009b).

Bu çalışma çerçevesinde, önceki çalışmaların (Boyle, 2009; Li \& Li, 2014; Nesbit, Belfer, \& Leacock, 2003; Saldana Hernandez vd., 2018; Saum, 2007) sonuçlarına dayalı olarak, öğrenme nesnelerinin geliştirilme sürecinde önemli olduğu düşünülen üç önemli kalite boyutu olan teknik kalite, içerik kalitesi ve pedagojik kalite (Nesbit vd., 2003; Lau \& Woods, 2008, 2009a) temelinde YNÖN tasarlanıp geliştirilmiştir. 


\section{Araştırmanın Amacı ve Önemi}

Mesleki ortaöğretim öğrencileri için YNÖN sentezlenmiş tasarım tabanlı araştırma yöntemi ile modellenmiştir. Sentezlenmiş tasarım tabanlı araştırma yöntemiyle öğrencilerin pedagojik kalite, içerik kalitesi ve teknik kalite algılarına göre kurgulanan YNÖN geliştirme sürecinin oluşturulması hedeflenmiştir. Bu bağlamda bu araştırmanında, öğrenme - öğretme sürecinde uygulanmak üzere geliştirilen YNÖN'nin; (a) öğrenme kapsamı, (b) öğrenme kazanımı, (c) etkileşim seviyesi, (ç) içeriğin modülerliği, (d) algılanan öğrenme ölçütleri, öğrenme nesnesinin pedagojik boyutunu ifade etmektedir. Teknik kalite boyutu, (a) dönüş süresi, (b) erişim kolaylığı, (c) kontrol duygusu, (d) yardım, (e) geri bildirim, (f) kayıt tutma ölçütlerini kapsamaktadır. İçerik kalitesi boyutu ise, (a) güncellik, (b) anlaşılabilirlik, (c) ilgililik, (ç) uyum, (d) içerik dizilimi, (e) içerik miktarı ölçütlerine karşılık gelmektedir. Bu doğrultuda bu araştırmanın amacı, YNÖN'nin pedagojik kalite, içerik kalitesi ve teknik kalite ölçütleri temelinde tasarlanması, geliştirilmesi ve değerlendirilmesidir.

Araştırma Problemi

Ortaöğretim düzeyindeki öğrenciler için YNÖN geliştirme süreci öğrenme nesnesi kalite ölçütlerine göre nasıl modellenmelidir?

\section{Alt Problemler}

- YNÖN öğrencilerin pedagojik kalite, içerik kalitesi ve teknik kalite algıları açısından ne düzeydedir?

- Öğrencilerin YNÖN geliştirme sürecine yönelik görüşleri nelerdir?

\section{Yöntem}

$\mathrm{Bu}$ araştırma, tasarım tabanlı araştırma yönteminin (McKenney \& Reeves, 2012) ilkeleri temelinde Van Wyk ve De Villiers (2014) tarafından geliştirilen sentezlenmiş tasarım tabanlı araştırma modeli temel alınarak desenlenmiştir.

\section{Katılımcilar}

Araştırma Ankara'daki bir ortaöğretim mesleki ve teknik eğitim kurumunun Bilişim Teknolojileri alanında 11. sınıf düzeyinde toplam 25 öğrencinin katılımıyla yürütülmüştür. 2018 - 2019 Güz döneminde birinci mezo döngü, 2018-2019 Bahar döneminde ise ikinci mezo döngü gerçekleştirilmiştir. Araştırma, modelin tüm sürecinin sınanabilmesi için YNÖN'nin geliştirilme sürecindeki kalite ölçütleriyle ilk kez karşılaşan ve YNÖN'nin geliştirilme sürecine dahil olmamış aynı sınıf düzeyinde farklı öğrenci gruplarıyla düzenlenmiştir. 
Veri Toplama Araçları

Öğrenme Nesnesi Kalite Rubriği (ÖNKR)

Lau ve Woods (2008) tarafından geliştirilen ve Özkök ve Akpolat (2020) tarafından Türkçe'ye uyarlanan Öğrenme Nesnesi Kabul Ölçeği'nin (ÖNKÖ) pedagojik kalite, içerik kalitesi ve teknik kalite boyutları, ÖNKR bağlamında araştırmacılar tarafından bu çalışmaya uyarlanmıştır. YNÖN, ÖNKÖ'nün 3 boyutunun araştırmacılar tarafından rubrik formatına uyarlanmasıyla hazırlanan ÖNKR kullanılarak değerlendirilmiştir.

ÖNKR, pedagojik kalite, içerik kalitesi ve teknik kalite olmak üzere üç ana boyut ve 17 alt boyuttan oluşmaktadır. Bu ana boyutlar ve alt boyutlar Tablo 1'de sunulmuştur.

Tablo 1. ÖNKR'nin ölçüt ve alt ölçütleri

\begin{tabular}{ll}
\hline \multicolumn{1}{c}{ Ölçütler } & \multicolumn{1}{c}{ Alt Ölçütler } \\
\hline \multirow{3}{*}{ Pedagojik Kalite } & Öğrenme kapsamı \\
& Ögrenme kazanımı \\
& Etkileşim seviyesi \\
& İçeriğin modülerliği \\
& Algıllanan öğrenme \\
\hline & Güncellik \\
& Anlaşıllabilirlik \\
& İlgililik \\
İçerik Kalitesi & Uyum \\
& İçerik dizilimi \\
& İçerik miktarı \\
\hline & Dönüş süresi \\
& Erişim kolaylı̆̆1 \\
& Kontrol duygusu \\
Teknik Kalite & Yardım \\
& Geri Bildirim \\
& Kayıt Tutma \\
\hline
\end{tabular}

ÖNKR'nin pedagojik kalite ölçütü; (a) öğrenme kapsamı, (b) öğrenme kazanımı, (c) etkileşim seviyesi, (ç) içeriğin modülerliği, (d) algılanan öğrenme alt ölçütlerinden oluşmaktadır. İçerik kalitesi ölçütü; (a) güncellik, (b) anlaşılabilirlik, (c) ilgililik, (ç) uyum, (d) içerik dizilimi, (e) içerik miktarı alt ölçütlerini içermektedir. Teknik kalite ölçütü; (a) dönüş süresi, (b) erişim kolaylığı, (c) kontrol duygusu, (d) yardım, (e) geri bildirim, (f) kayıt tutma alt ölçütlerini kapsamaktadır.

Görüşme Formları

Öğrencilerin sürece yönelik görüşlerini belirlemek amacıyla KEFE (SWOT) analizi temel alınarak görüşme formları düzenlenmiştir. Öğrenci formu "YNÖN'de öğrenmeme katkı sağlayan şeyler", “YNÖN'de öğrenmeme katkısı olmayan şeyler", "YNÖN'de 
öğrenmemi kolaylaştıran şeyler" ve "YNÖN'de öğrenmemi zorlaştıran şeyler" başlıklarından oluşturulmuştur.

Veri Analizi

ÖNKR rubrik puanlarının analizi, IBM SPSS Statistics V22.0 programı aracılığıyla betimleyici istatistiksel yöntemler (frekans ve yüzde) kullanılarak analiz edilmiştir. Her iki mezo döngü sonunda öğrencilerden alınan yansımaların verileri, içerik analizi ile çözümlenmiştir. İçerik analizinde, benzer olan veriler ortak kavram ve temalar altında birleştirilir ve anlaşılır şekilde okuyucuya sunulur (Yıldırım \& Şimşek, 2013). Veri analizi sürecinde, (1) ham verilerin içerik analizine hazırlanması, (2) ön tema ve kod listesinin oluşturulması, (3) verilerin tamamını okuma ve kodlama, (4) kod ve temaların düzenlenmesi ve (5) bulguların tanımlanması ve yorumlanması aşamaları takip edilmiştir (Yıldırım \& Şimşek, 2013). Veri analizinin ilk aşaması olan ham verilerin içerik analizine hazırlanması sürecinde, ses kayıtları ve görüşme sırasında alınan notlar metne dökülmüştür. YNÖN'nin güçlü yönleri, zayıf yönleri, sunduğu fırsatlar ve içerdiği tehditler ana kategorilerinden hareketle ön tema ve kod listesi hazırlanmıştır. Belirlenen kategorilere göre düzenlenen tema ve kodlar, alt problemlerle ilişkili olarak yorumlanmıştır.

\section{Araştırmanın Modeli}

Araştırma, Van Wyk ve De Villiers (2014) tarafından geliştirilen sentezlenmiş tasarım tabanlı araştırma yöntemiyle tasarlanmıştır. İki mezo döngü de "problem analizi”, "çözüm tasarlama", "çözüm geliştirme", "uygulamada değerlendirme" ve "yansıma" mikro döngülerinden oluşmaktadır. Sentezlenmiş tasarım tabanlı araştırma modelinin süreç akış diyagramı Şekil 1'de sunulmuştur.

Şekil 1 incelendiğinde her iki mezo döngünün de beş mikro döngüden oluştuğu görülmektedir. Bu mikro döngülerin her biri şu şekilde açılanabilir: 


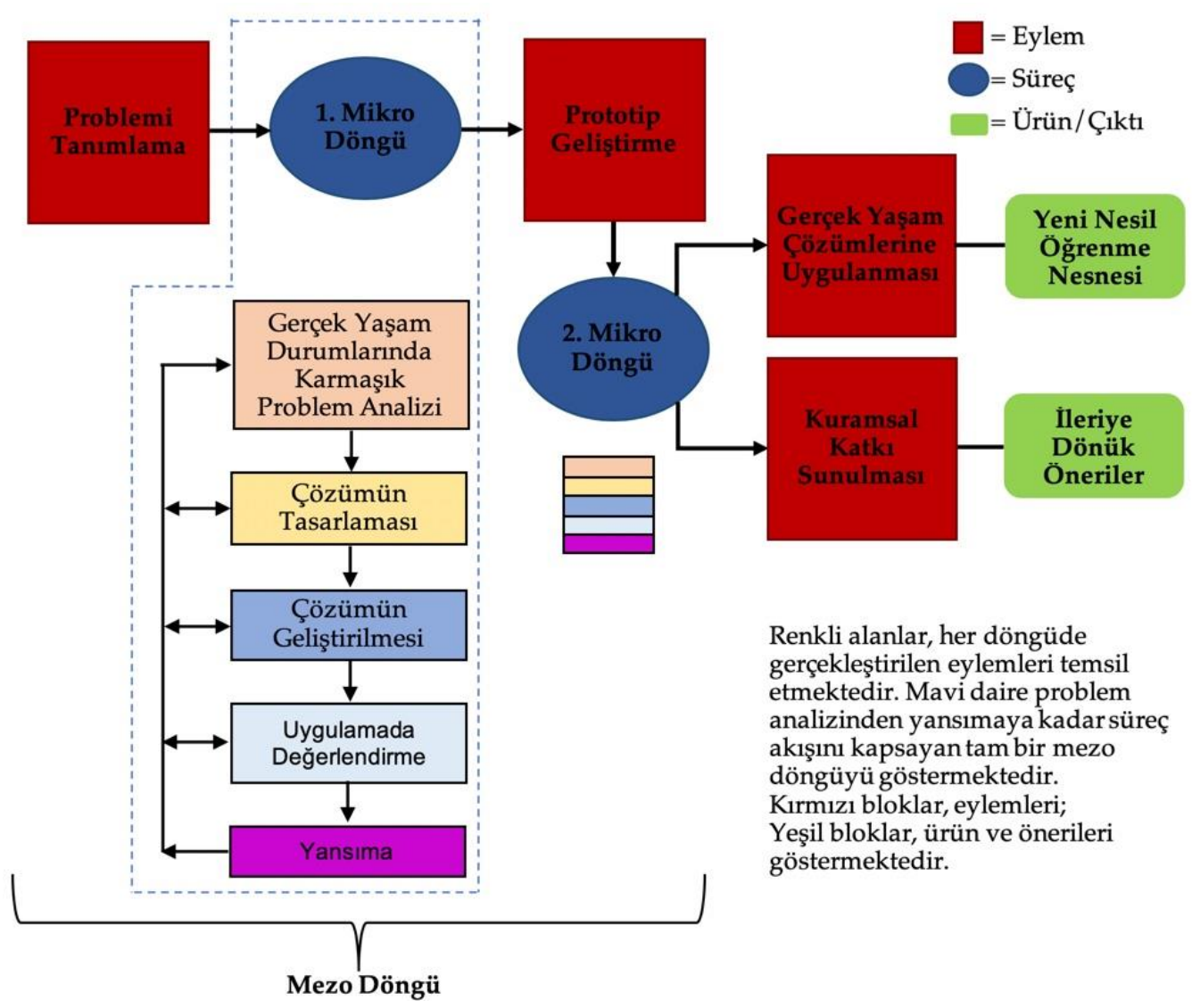

Şekil 1. Araştırmada yürütülen mezo ve mikro döngüler

(a) Problem analizi; araştırma sürecine yönelik uygulama sürecini etkileyebilecek etmenler açısından analiz ve incelemeler yapılır. (b) Çözüm tasarlama; problemi ele alan olası taslak uygulamalar / prototip önerilir. Döngünün sonunda son taslak uygulamanın tasarımı şekillendirilerek son hali verilir. (c) Çözüm geliştirme; belirlenen taslak uygulama tasarım ilkeleri ve teknolojik yenilikler dâhilinde geliştirme sürecine başlanır. Uygulama, tasarım evresinden elde edilen bilgiler ve sonuçlarına göre geliştirilir. (ç) uygulamada değerlendirme; ürün gerçek hayat durumlarında test edilir. (d) yansıma; uygulamaya yönelik gerçek yaşam durumlarına katkı sağlayacak ve problemin çözümü için teorik katkı olacak şekilde uygulama sonuçları ortaya çıkarılır.

Şekil 2'de sentezlenmiş tasarım tabanlı araştırma yönteminin her bir mezo döngüsünün mikro döngü adımları ve süreç-sonuç ilişkileri sunulmuştur. 
SÜREÇ

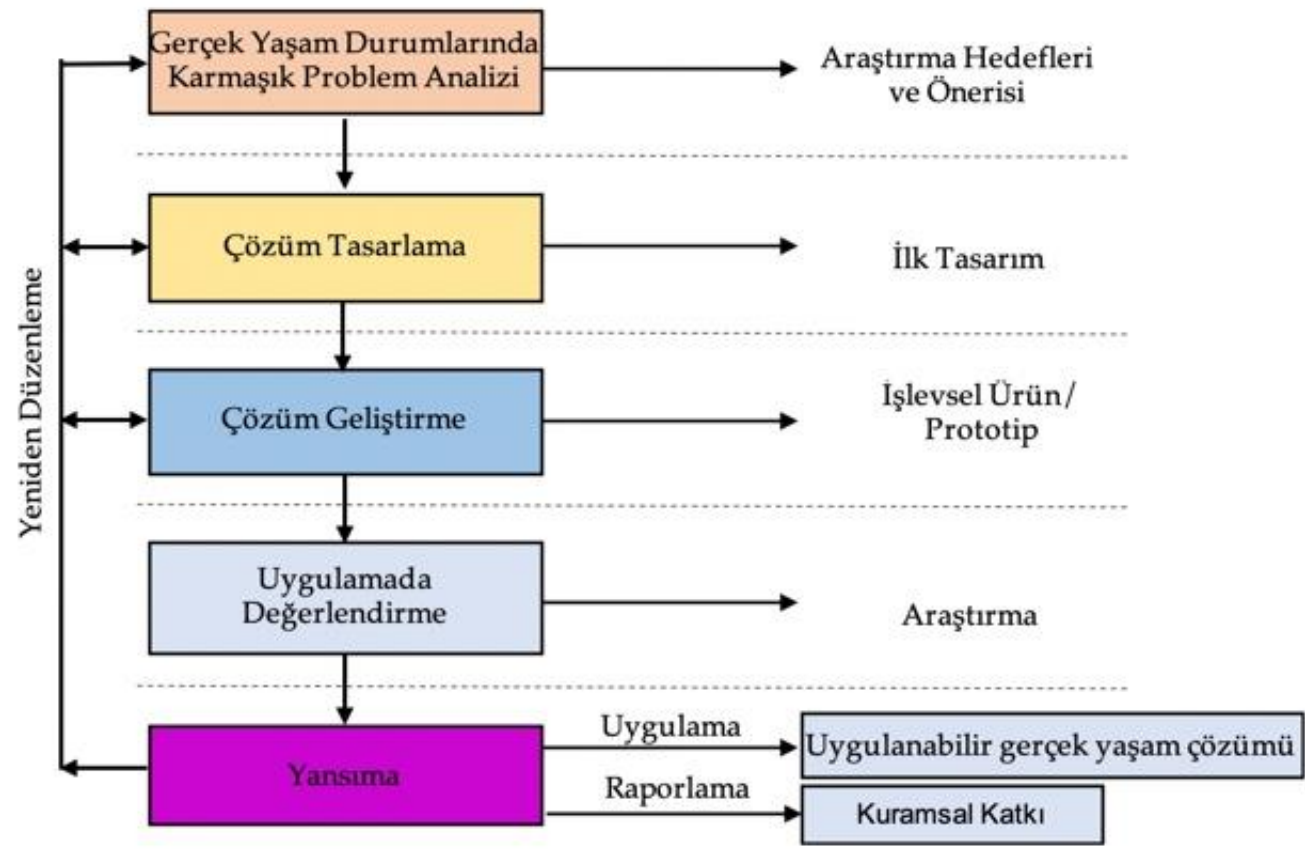

Şekil 2. Sentezlenmiş tasarım tabanlı araştırma yönteminde mikro döngü süreçleri ve sonuçları

Birinci Mezo Döng̈̈

Araştırmanın ilk mezo döngüsü, problem analizi, çözüm tasarlama, çözüm geliştirme, uygulamada değerlendirme ve yansıma mikro döngülerini içermektedir. Birinci mezo döngü 2018 - 2019 öğretim yılı güz döneminde 3 haftalık bir süreçte, haftada 2 saat olacak şekilde gerçekleştirilmiştir. Birinci mezo döngüde YNÖN'nin geliştirme sürecinin öğrenme nesnesi kalite ölçütlerine göre modellendiği aşamaları bütüncül olarak Tablo 2'de sunulmuştur.

Tablo 2. Birinci mezo döngüde öğrenme nesnesi kalite ölçütlerine göre YNÖN geliştirme süreci aşamaları

\begin{tabular}{lll}
\hline Mikro Döngüler & \multicolumn{1}{c}{ Ölçütler } & \multicolumn{1}{c}{ Alt Ölçütler } \\
\hline & & Öğrenme kapsamı \\
Problem Analizi & Öğrenme kazanımı \\
& & Etkileşim seviyesi \\
& & İçeriğin modülerliği \\
& Algıllanan öğrenme \\
\hline & Güncellik \\
& & Anlaşılabilirlik \\
& & İlgililik \\
& İçerik Kalitesi & Uyum \\
& & İçerik dizilimi \\
& & Icerik miktarı \\
\hline
\end{tabular}




\begin{tabular}{|c|c|c|}
\hline Çözüm Geliştirme & Teknik Kalite & $\begin{array}{l}\text { Dönüşs süresi } \\
\text { Erişim kolaylı̆̆1 } \\
\text { Kontrol duygusu } \\
\text { Yardım } \\
\text { Geri Bildirim } \\
\text { Kayıt Tutma }\end{array}$ \\
\hline Uygulamada Değerlendirme & Öğrenci geri bildirim & \\
\hline Yansima & $\begin{array}{l}\text { Öğrenci yansıma } \\
\text { Öğretmen yansıma }\end{array}$ & \\
\hline
\end{tabular}

Tablo 2 incelendiğinde ilk mezo döngüdeki her bir mikro döngünün adımları ile bu adımların YNÖN'nin hangi ana ve alt ölçütlerine karşılık geldiği görülmektedir. Pedagojik kalite, içerik kalitesi ve teknik kalite ölçütleri her bir mikro döngü içine yerleştirilmiştir. İlk mezo döngünün her bir mikro döngüsünde pedagojik kalite, içerik kalitesi ve teknik kalite uygulamalarının dahil edildiği geliştirme aşamaları daha detaylı bir biçimde Şekil 3'de görülmektedir.

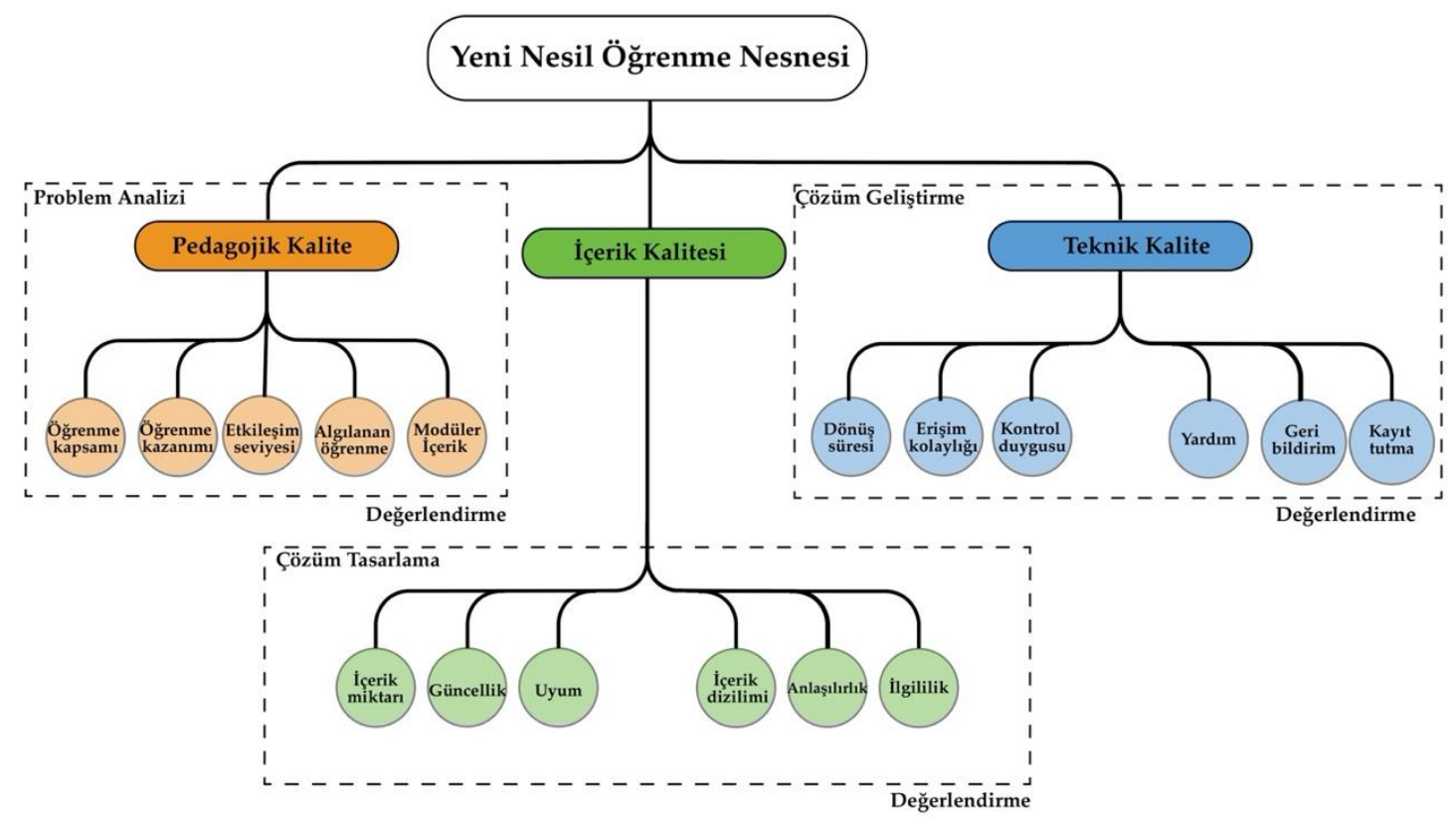

Şekil 3. Birinci mezo döngüde YNÖN geliştirme aşamaları

Aşağıda ilk mezo döngünün her bir mikro döngüsü detaylarıyla açıklanmaktadır.

Problem Analizi

Problem analizi ilk mikro döngü olması nedeniyle araştırma bağlamına yönelik kapsamlı analiz ve inceleme çalışmalarından oluşmaktadır. Uygulayıcı ve araştırmacı arasında anlamlı işbirliğinin kurulabilmesi ve araştırma bağlamının koşullarının belirlenmesi için bu döngüde 3 Bilişim Teknolojileri öğretmeniyle toplam 4 toplantı gerçekleştirilmiştir.

Problem analizi mikro döngüsünde, geliştirilecek YNÖN'nin içeriği için İnternet Programcılı̆̆ı dersi kapsamına giren uygulanabilir ve özgün bir problemin belirlenmesine 
karar verilmiştir. Bilişim Teknolojileri öğretmeninin aktif olacağ1 süreçte konu itibariyle İnternet Programcılığı dersinin bu uygulama için uygun olabileceği görüşüne varılmıştır. Öğrencilerin dijital araçları kullanabilme bilgi ve becerileri göz önünde bulundurularak uygulamanın ortaöğretim 11. sınıf düzeyinde yapılmasına karar verilmiştir. Toplantılarda, YNÖN'nin pedagojik, içerik ve teknik kapsamına odaklanılarak, mevcut çoklu ortam materyalleri, öğrenme nesnesi kalite ölçütleri açısından incelenmiştir.

Bilişim Teknolojileri öğretmenleri ile geliştirilmesi planlanan YNÖN'nin pedagojik, içerik ve teknik kapsamı için uygun kazanımların ve etkinliklerin planlaması yapılmıştır. Öğrencilerin içerik olarak İnternet Programcılığı dersindeki “Açık Kaynak Kodla Temel Uygulamalar" ünitesinde zorluk yaşadıkları noktalar üzerinde durulmuştur. Öğrenciler soyut düşünmekte zorlanmaktadır. Öğrencilerin soyut düşünme becerileri programlama öğreniminde yetersiz kalmaktadır. Öğrenme - öğretme sürecine yönelik üst düzey düşünme becerilerinin geliştirilmesine yönelik destekleyici öğrenme materyallerine ihtiyaç vardır. YNÖN'nin planlanan tasarım kurgusunda bu nokta üzerinde durulmuştur. Geliştirilecek YNÖN'nin kapsamı (a) pedagojik açıdan disiplinler arası etkileşimli processing programlama uygulaması, (b) içerik olarak İnternet Programcılığı dersindeki “Açık Kaynak Kodla Temel Uygulamalar" ünitesindeki kazanımlar ve (c) teknik olarak, öğrencinin etkileşimli YNÖN kullanımını etkileyen teknik özellikleri içermektedir.

İnternet Programcılığı dersindeki “Açık Kaynak Kodla Temel Uygulamalar” ünitesi kapsamında kararlaştırılan YNÖN'nin kapsamı konusunda öğretmenler, derslerinde kullandıkları mevcut çoklu ortam materyallerinin görsel ve sözel unsurları bağlamında;

(a) içeriğin güncel bilgi ve kapsamı içermesi, işlenen konuyla ilişkisi, anlaşılabilirliği ve öğrencilerin öğrenme ihtiyaçlarını karşılayabilmesi,

(b) etkileşimli öğretimsel aktivite eksikliği, dersin öğrenme amacı ve hedefine karşılık gelmemesi, öğrencinin öğrenme gereksinimlerini karşılamaması,

(c) öğrenme nesnesinin kullanımına yönelik erişim, etkileşim, farklı platformlarda çalışabilirlik gibi teknik konularda sıkıntı yaşadıklarını belirtmişlerdir.

$\mathrm{Bu}$ durumun, öğrencilerin öğrenme nesnelerine yönelik pedagojik kalite, içerik kalitesi ve teknik kalite algılarında olumsuz sorunlar oluşturduğuna vurgu yapmışlardır. Problem analizi mikro döngüsünün sonunda, araştırmacılar ve uygulayıcılar araştırma hedeflerini belirleyerek araştırma stratejisine karar vermişlerdir. 


\section{Çözüm Tasarlama}

Çözüm tasarlama mikro döngüsünde, problem analizi mikro döngüsünde öğretmenlerle iş birliği halinde belirlenen gereksinimlere ve alanyazına göre YNÖN geliştirme süreci detaylandırılmış, öngörülen süreç modeli ve adımları belirlenmiştir. Şekil 3’de çözüm tasarlama uygulama adımları tek tek gösterilmektedir.

Problem analizi mikro döngüsünde ulaşılan çıkarımlar ve öğretmenlerin sürece yönelik önerileri temelinde araştırmacılar tarafından YNÖN'nin içerik, pedagojik ve teknik özelliklerini içeren prototip taslağı hazırlanmıştır. Hazırlanan YNÖN prototipi ortaöğretim öğrencilerinin kavrayabileceği ve gerçekleştirebileceği düzeye indirgenmiştir.

YNÖN'nin prototipi, İnternet Programcılığı dersindeki “Açık Kaynak Kodla Temel Uygulamalar" ünitesini işlemeleriyle başlatılmıştır. Öğrenciler, ünitenin öğretme ve öğrenme sürecinde YNÖN prototip etkinliğinden haberdar edilmişlerdir.

İnternet Programcılığı dersindeki “Açık Kaynak Kodla Temel Uygulamalar” ünitesi kapsamında YNÖN'nin prototipi üzerinde etkileşimli processing programlamanın temel kod bilgileri ve örnek uygulamaları gösterilmiştir. Ünite kapsamında; (a) processing programlama nedir?, (b) processing ortamı, (c) değişkenler, (ç) fonksiyonlar, (d) renk, (e) koordinat sistemi, (f) temel şekiller, (g) processing kodlama ile farklı geometrik şekiller yaratma, (h) processing kodlama ile farklı kenar uzunlukları ve farklı açılardan oluşan geometrik şekillerle isim yazma, (1) processing kodlama ile farklı uzunluktaki doğru parçaları ile üçgen, dörtgen, beşgen ve altıgen formlar yaratma, (i) processing kodlama ile kompozisyon oluşturma etkinliklerine yer verilmiştir.

\section{Çözüm Geliştirme}

İnternet Programcılı̆̆ı dersindeki "Açık Kaynak Kodla Temel Uygulamalar" ünitesinin ilgili kazanımlarının ele alınmasının ardından YNÖN'si geliştirme aşamasına geçilmiştir. Çözüm tasarlama mikro döngüsü stratejisinin oluşturulmasını, çözüm geliştirme mikro döngüsünün adımlarının uygulanması takip etmiştir. Öğrencilerle 3 hafta bilgisayar laboratuvarında bir araya gelinmiş, YNÖN uygulamalarını tamamlayarak Bilişim Teknolojileri öğretmenlerine teslim etmeleri istenmiştir. Şekil 4'te YNÖN'ne göre geliştirilen processing programlama uygulaması örneklerine yer verilmiştir. 


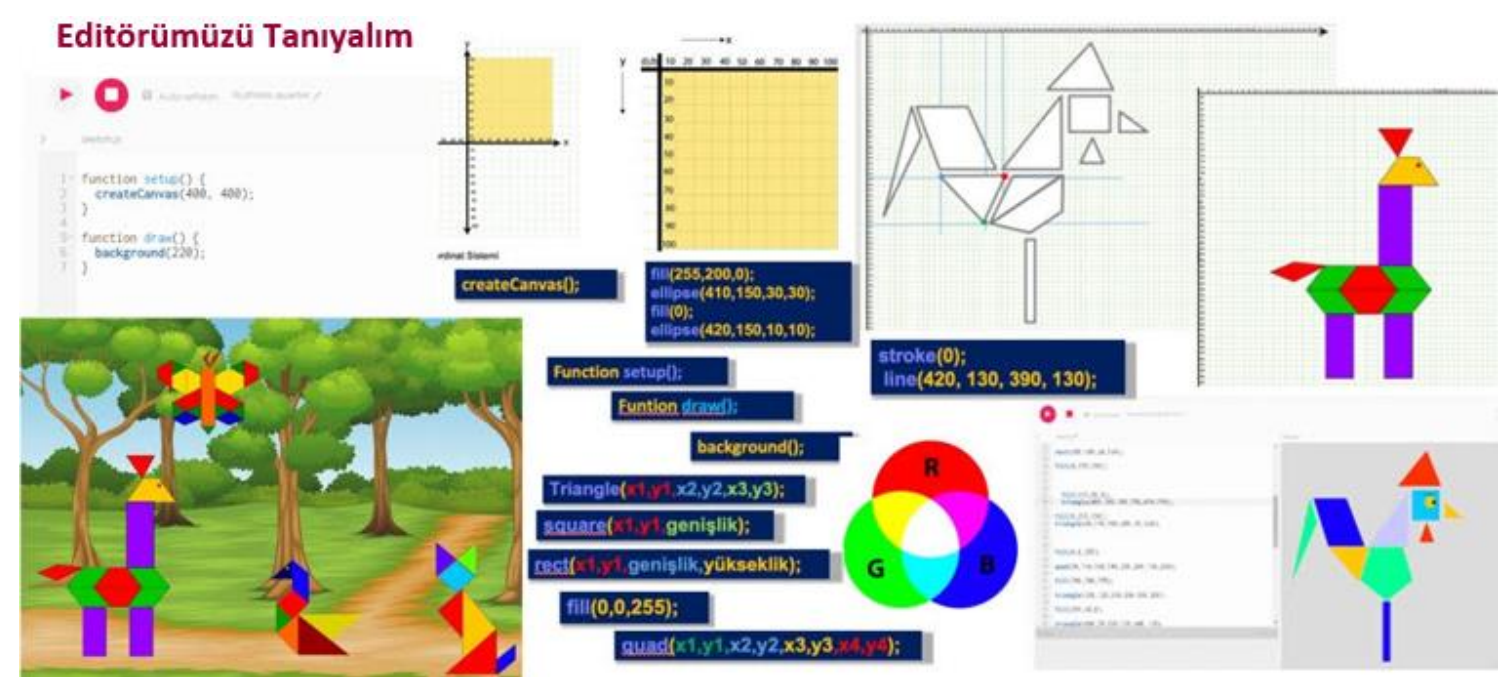

Şekil 4. Birinci mezo döngüde öğrencilerin YNÖN kullanarak geliştirdikleri processing

uygulamasindan örnekler

Uygulamada Değerlendirme

YNÖN geliştirme süreci ve modeli, ÖNKR'den elde edilen bulgular ile öğrencilerin yansımaları doğrultusunda değerlendirilmiştir. ÖNKR'den elde edilen sonuçlar Tablo 3'de sunulmuştur.

Tablo 3. Birinci mezo döngünün ÖNKR sonuçları

\begin{tabular}{|c|c|c|}
\hline Ölçütler & $\overline{\mathbf{X}}$ & S.S. \\
\hline Öğrenme Nesnesi Kalite Ölçütleri & 2,64 & 0,67 \\
\hline İçerik Kalitesi & 2,71 & 0,68 \\
\hline İçerik miktarı & 2,52 & 0,65 \\
\hline Güncellik & 2,96 & 0,73 \\
\hline Uyum & 2,76 & 0,82 \\
\hline İçerik dizilimi & 2,12 & 0,96 \\
\hline Anlaşılabilirlik & 3,04 & 0,28 \\
\hline İlgililik & 2,88 & 0,67 \\
\hline Pedagojik Kalite & 2,78 & 0,52 \\
\hline Öğrenme kapsamı & 2,81 & 0,58 \\
\hline Öğrenme kazanımı & 2,48 & 0,75 \\
\hline Etkileşim seviyesi & 2,76 & 0,60 \\
\hline İçeriğin modülerliği & 2,93 & 0,36 \\
\hline Algilanan öğrenme & 2,96 & 0,32 \\
\hline Teknik Kalite & 2,43 & 0,83 \\
\hline Dönüş süresi & 2,54 & 0,54 \\
\hline Erişim kolaylığı & 2,44 & 0,58 \\
\hline Kontrol duygusu & 2,12 & 1,02 \\
\hline Yardım & 2,86 & 0,71 \\
\hline Geri bildirim & 2,08 & 1,27 \\
\hline Kayıt tutma & 2,56 & 0,88 \\
\hline
\end{tabular}


Tablo 3'de sunulan ilk mezo döngünün ÖNKR sonuçları incelendiğinde, içerik kalitesi ölçütünün $\overline{\mathrm{X}}=2,71$, pedagojik kalite ölçütünün $\overline{\mathrm{X}}=2,78$ ve teknik kalite ölçütünün $\overline{\mathrm{X}}=$ 2,43 olduğu bulunmuştur. İçerik kalitesi ölçütünde; içerik miktarı $\overline{\mathrm{X}}=2,52$, güncellik $\overline{\mathrm{X}}=2,96$, uyum $\bar{X}=2,76$, içerik dizilimi $\bar{X}=2,12$, anlaşılabilirlik $\bar{X}=3,04$, ve ilgililik $\bar{X}=2,88$ sonuçları elde edilmiştir. Pedagojik kalite ölçütünde; öğrenme kapsamı $\overline{\mathrm{X}}=2,81$, öğrenme kazanımı $\overline{\mathrm{X}}=2,48$, etkileşim seviyesi $\bar{X}=2,76$, içeriğin modülerliği $\bar{X}=2,93$ ve algılanan öğrenme $\bar{X}=2,96$ olduğu görülmüştür. Son olarak teknik kalite ölçütünde; dönüşs süresi $\bar{X}=2,54$, erişim kolaylığg $\overline{\mathrm{X}}=$ 2,44 , kontrol duygusu $\bar{X}=2,12$, yardım $\bar{X}=2,86$, geri bildirim $\bar{X}=2,08$ ve kayıt tutma $\bar{X}=2,56$ olduğu şeklinde bulgulara ulaşılmıştır.

\section{Yansima}

Birinci mezo döngüde öğrencilerin YNÖN geliştirme sürecindeki yansımalarına ilişkin tema, kod, frekans ve yüzdeler Tablo 4' de sunulmuştur.

Tablo 4. Birinci mezo döngüde öğrencilerin sürece yönelik yansımalarına ilişkin tema, kod, frekans ve yüzdeler

\begin{tabular}{llcc}
\multicolumn{1}{c}{ Tema } & \multicolumn{1}{c}{ Kod } & Frekans & Yüzde \\
\hline YNÖN'nin öğrenmeme katkısı & İçerik miktarı & 12 & 48 \\
sağlayan özellikleri & Etkileşim düzeyi & 13 & 52 \\
& Erişim kolaylığı & 17 & 68 \\
\hline \multirow{2}{*}{$\begin{array}{l}\text { YNÖN'nin öğrenmeme katkısı } \\
\text { olmayan özellikleri }\end{array}$} & İlgililik & 9 & 36 \\
& Dönüşsüresi & 8 & 32 \\
& Kontrol duygusu & 12 & 48 \\
\hline YNÖN ile öğrenmemi & Dijital ortamda çalışma & 10 & 40 \\
kolaylaştıran şeyler & Disiplinler arası işleniş & 25 & 100 \\
\hline \multirow{2}{*}{$\begin{array}{l}\text { YNÖN ile öğrenmemi zorlaştıran } \\
\text { şeyler }\end{array}$} & İnternet kaynaklı sorunlar & 19 & 76 \\
& İşletim sistemi-yazılım & 15 & 60 \\
\hline Öğrenci Sayısı & uyumsuzluğu kaynaklı sorunlar & & \\
\hline & & 25 & 100 \\
\hline
\end{tabular}

Tablo 4'de sunulan YNÖN geliştirme süreci yansımaları incelendiğinde, YNÖN'ni deneyimleyen öğrencilerin \%48'i YNÖN'nin içerik miktarının, \%52'si YNÖN'nin etkileşim özelliğinin ve \%68'i de YNÖN'ne erişim kolaylı̆̆ının, öğrenmelerine katkı sağladığını, herhangi bir problem yaşamadıklarını ve kendilerini bu noktalarda yeterli algıladıklarını belirtmişlerdir. Öğrencilerin \%36'sı YNÖN'nin ders içeriği ile ilgililik düzeyi, \%32'si dönüş süresi ve \%48'i YNÖN'sini kontrol edebilme özelliğinin YNÖN'ne dönük algilarına ve öğrenmelerine katkı sağlamadığını belirtmişlerdir. YNÖN ile öğrenmeyi kolaylaştıran etmenlere gelindiğinde ise, öğrencilerin $\% 40$ ' 1 YNÖN'si ile dijital ortamda çalışmanın ve \%100'ü disiplinler arası işlenişin öğrenmelerini kolaylaştırdığına vurgu yapmışlardır. YNÖN'ni deneyimleyen öğrencilerin \%76'sı internet kaynaklı sorunlara ve \%60'1 işletim 
sistemi yazılım uyumsuzluğu kaynaklı sorunlara dikkat çekerek, YNÖN'ni kullanımının öğrenmelerini zorlaştırdığına işaret etmişlerdir.

Birinci mezo döngüde, YNÖN'nin geliştirme sürecini deneyimleyen öğrencilerin rubrik ve yansıma sonuçlarını destekleyici nitelikte olabilecek sürece aktif katılım sağlayan öğrencilerin geliştirme sürecine dönük olumlu ve olumsuz görüşleri ve önerileri aşağıda belirtilmiştir.

"Koordinat sisteminin çizgilerini görmediğimiz için nesnelerin yerlerini ayarlamamız zaman aldı.Farkh bir ürün ortaya çıkardım. Kodların kısa ve tek satırlık olması da beni motive etti." (Ö5)

"Kullandığımız öğrenme materyali basit anlatımının yer alması beni olumlu etkiledi." (Ö6)

"Etkileşimli ortamda kod yazmaya aşina olmadığım için ilk başta zorlandım." (Ö8)

"Mantı̆̆ııı kavrayana kadar çok zorlandım, sürekli farkh şekiller oluşturdum. Bu süreçte çok zor öğrendim." (Ö11)

"Bence çok zorlayıcı aşırı bir zaman gerektiriyor. Kodları deneyerek yazdım." (Ö12)

"Kodlayarak çizim yapıyor da olsak, her uygulamadan önce kâğıt taslak kullanmanın gerekli olduğunu öğrendim." (Ö20)

"Görsel olması ve bilgileri somutlaştırılması çok öğreticiydi." (Ö25)

İkinci Mezo Döngü

Birinci mezo döngüde YNÖN kapsamında yapılan etkileşimli kodlama uygulamasının daha da basitleştirilmesinin gerektiği görülmüştür. Ayrıca öğrenci görüşleriyle ulaşılan bulgular doğrultusunda YNÖN prototip içeriğinde değişikliğe karar verilmiştir. Bu gereksinimlerden hareketle ikinci mezo döngü 2018 - 2019 eğitim - öğretim yılı Bahar döneminde 2 haftalık bir süreçte haftada 4 saat olacak şekilde gerçekleştirilmiştir. İkinci mezo döngünün mikro döngülerinde iyileştirmeler yapılarak ve YNÖN'nin içeriğinde yeni çözümler ve tercihler üretilmeye çalışılmıştır. Şekil 5'de 2. mezo döngüdeki YNÖN geliştirme aşamaları sunulmuştur.

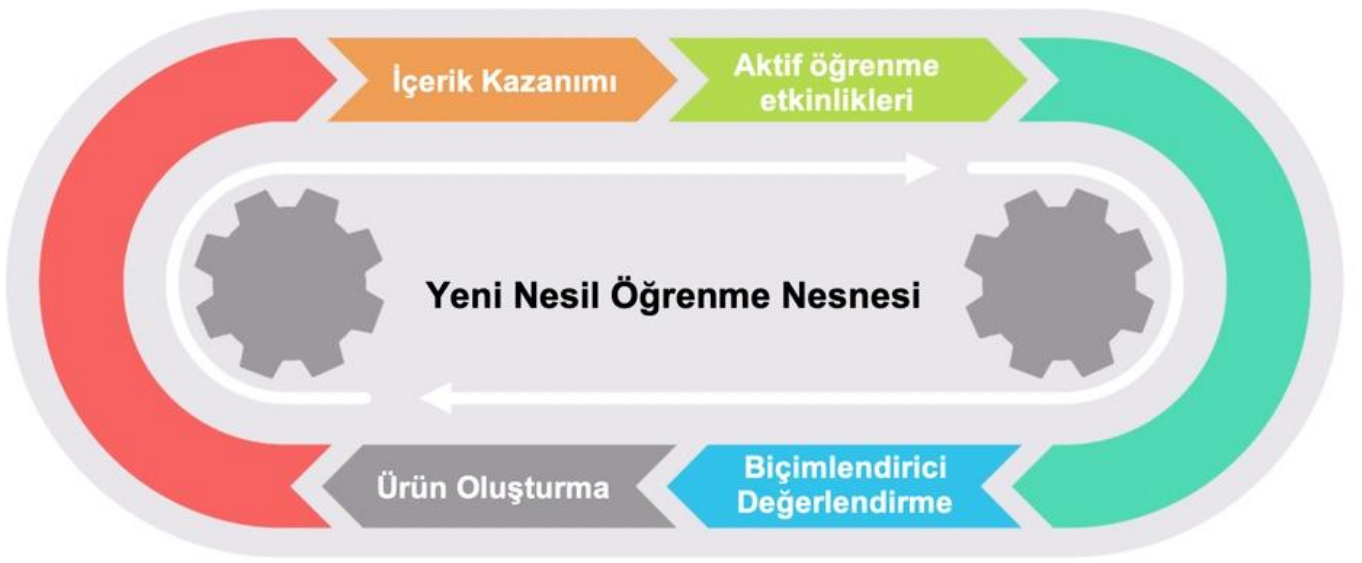

Şekil 5. İkinci mezo döngünün YNÖN geliştirme aşamaları 


\section{Problem Analizi}

İkinci mezo döngüde, ilk mezo döngüde de yer alan, (a) içerik kalitesi ölçütünün alt ölçütleri içerik miktarı, güncellik, uyum, içerik dizilimi, anlaşılabilirlik ve ilgililik, (b) pedagojik kalite ölçütünün alt ölçütleri, öğrenme kapsamı, öğrenme kazanımı, etkileşim seviyesi, içeriğin modülerliği ve algılanan öğrenme, (c) teknik kalite ölçütünün alt ölçütleri dönüş süresi, erişim kolaylığı, kontrol duygusu, yardım, kayıt tutma ve geri bildirim şeklindeki ağaç yapısı (Şekil 3’de görülen yapı), sarmal bir yapıda tekrar düzenlenmiştir. YNÖN etkileşimli yapısı yeniden düzenlenmiş ve uygulama yönergesi güncellenmiş, processing hazır kodlardan oluşan etkinlikler planlanmıştır. Processing işlem adımları sadeleştirilerek öğrencilere sunulmuştur.

İnternet Programcılığı dersindeki "Açık Kaynak Kodla Temel Uygulamalar" ünitesinde processing kavramının işlenmesiyle başlayan süreç, programlama ve processing kavramlarına odaklanan sunu ve etkinliklerle devam etmiştir.

\section{Çözüm Tasarlama}

Birinci döngüde olduğu gibi "processing nedir?" sorusuna yönelik yeniden düzenlenmiş olan YNÖN sunulmuştur. Ek olarak hazırlanan yönergede farklı çalışma örnekleri kullanılmıştır. Yeniden düzenlenen yönergede öğrencilerin processing programlama dilini bütünüyle görmeleri için processing uygulama örnekleri hazırlanıp öğrencilere dağıtılmıştır. Birinci mezo döngü çözüm tasarlama döngüsünden farklı olarak, öğrencilerden yönergedeki adımları takip ederek hazır processing programlama kodları ile örnek uygulama yapmaları istenmiştir.

\section{Çözüm Geliştirme}

Çözüm tasarlama mikro döngüsünün hemen ardından sarmal yapıda yer alan çözüm geliştirme aşamasına geçilmiştir. Çözüm geliştirme mikro döngüsünde öğrenciler, YNÖN geliştirme ortamında processing programlama uygulamasını hazır kod setleri kullanarak gerçekleştirmişlerdir. Öğrenciler oluşturulan geometri temalı tangram ve kendi isimlerini processing programlama dili ile etkileşimli olarak yazmışlardır. YNÖN kod paneline yazdıkları kodlar diğer arayüzde tangrama dönüşmüştür. Tangramların nasıl olması gerektiğine karar verilirken processing programlama hazır kodları kullanılmış, processing yazılımının kendi kütüphanesinde yer alan kod setlerinden uygun olanlar seçilmiştir.

Bilgisayarlarda YNÖN yazılımının sorunsuz çalışıp çalışmadığ1 kontrol edilmiştir. Daha sonra tangram ve geometrik isim temalı hazır kod setleri öğrenciler tarafından 
processing programlama dili kullanılarak gerçekleştirilmiştir. Processing kodlama sonucunda YNÖN, etkileşimli, renkli ve eğlenceli grafikler ile görünür hale getirilmiştir. Öğrencilerin YNÖN üzerinde kodların tangram ve geometrik şekillere dönüştürülme aşamaları iç içe geçecek şekilde yapılandırılmıştır. Şekil $6^{\prime}$ da birinci ve ikinci mezo döngülerde öğrencilerin YNÖN ile processing kodlama ve tangram görselleştirirken çekilmiş görüntülerine yer verilmiştir.

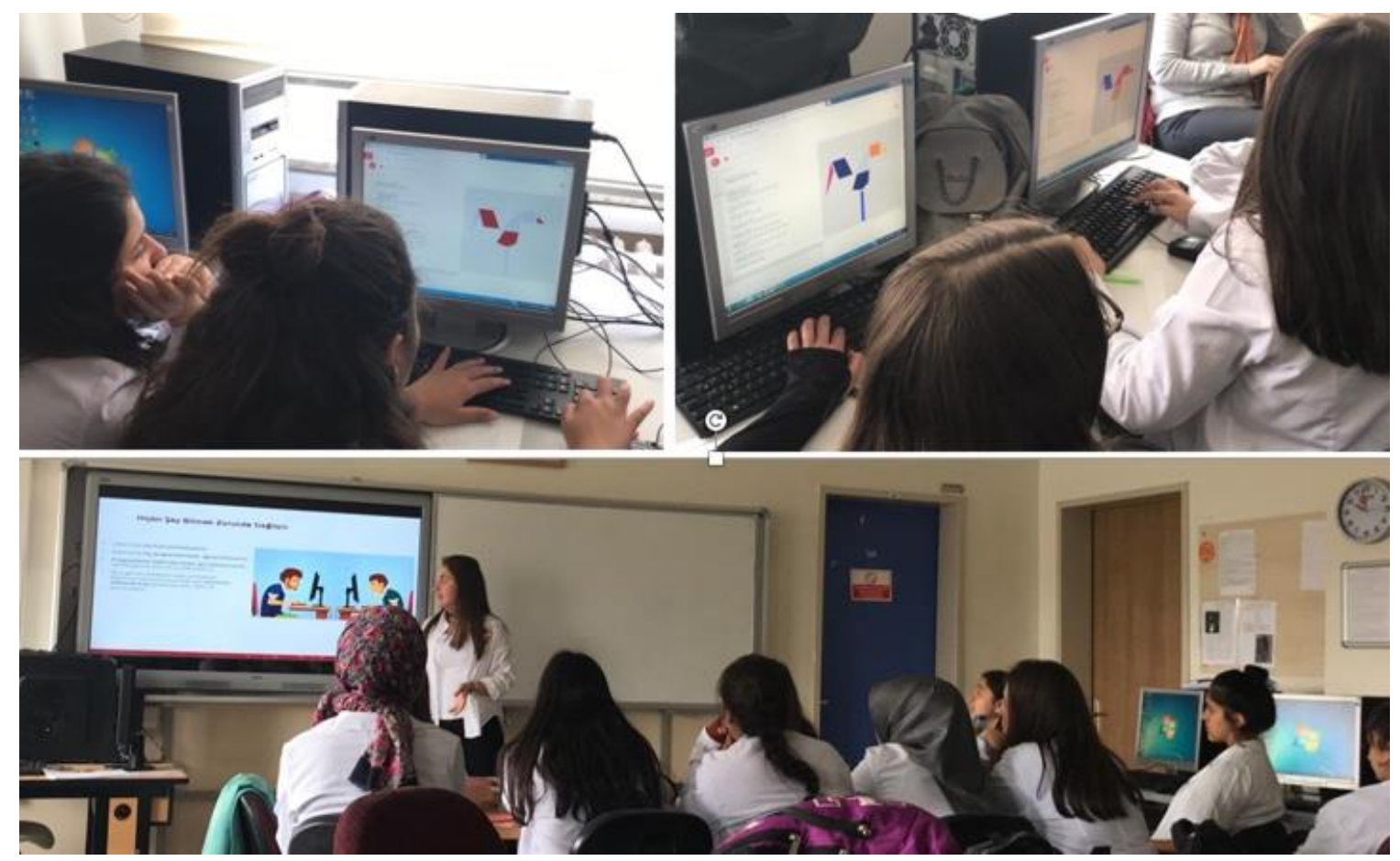

Şekil 6. Birinci ve ikinci mezo döngüde öğrencilerin ynön'ni deneyimleme sürecine ilişkin örnek

Uygulamada Değerlendirme görünümler

İkinci mezo döngü çözüm geliştirme mikro döngüsünün tamamlanmasının ardından değerlendirme mikro döngüsü ile devam etmiştir. İkinci mezo döngüde ÖNKR'den elde edilen sonuçlar Tablo 5'de sunulmuştur.

Tablo 5. İkinci mezo döngünün ÖNKR sonuçları

\begin{tabular}{lcc}
\hline \multicolumn{1}{c}{ Ölçütler } & $\overline{\mathbf{X}}$ & S.S. \\
\hline Öğrenme Nesnesi Kalite Ölçütleri & $\mathbf{2 , 9 2}$ & $\mathbf{0 , 4 7}$ \\
\hline İçerik Kalitesi & $\mathbf{3 , 0 4}$ & $\mathbf{0 , 3 6}$ \\
\hline İcrik miktarı & 3,26 & 0,44 \\
Güncellik & 3,14 & 0,33 \\
Uyum & 2,88 & 0,41 \\
İçerik dizilimi & 3,01 & 0,24 \\
Anlaşılabilirlik & 3,04 & 0,19 \\
İlgililik & 2,93 & 0,57 \\
\hline
\end{tabular}


Özkök \& Yllmaz

\begin{tabular}{llc}
\hline Pedagojik Kalite & $\mathbf{3 , 0 4}$ & $\mathbf{0 , 4 4}$ \\
\hline Öğrenme kapsamı & 3,08 & 0,41 \\
Öğrenme kazanımı & 2,94 & 0,49 \\
Etkileşim seviyesi & 2,98 & 0,56 \\
İçeriğin modülerliği & 3,04 & 0,37 \\
Algılanan öğrenme & 3,16 & 0,41 \\
\hline Teknik Kalite & $\mathbf{2 , 6 9}$ & $\mathbf{0 , 6 3}$ \\
\hline Dönüş süresi & 2,84 & 0,33 \\
Erişim kolaylığ1 & 2,88 & 0,47 \\
Kontrol duygusu & 2,76 & 0,28 \\
Yardım & 2,86 & 0,41 \\
Geri Bildirim & 2,11 & 1,21 \\
Kayıt Tutma & 2,71 & 0,63 \\
\hline
\end{tabular}

ÖNKR sonuçları incelendiğinde içerik kalitesi $\bar{X}=3,04$, pedagojik kalite $\bar{X}=3,04$, teknik kalite $\bar{X}=2,69$ bulgularıyla, ilk mezo döngüye göre yükselme olduğu görülmektedir. Özellikle içerik miktarı $\overline{\mathrm{X}}=3,04$ ölçütünde ulaşılan düzey dikkati çekmektedir. Pedagojik kalite ölçütünün, öğretim stratejisinde yapılan yeniden düzenleme sonucunda öğrenme kazanımı alt ölçütü $\bar{X}=2,94$ düzeyine yükselmiştir. Teknik kalite ölçütünün alt ölçütü olan erişim kolaylığının $\overline{\mathrm{X}}=2,88$ düzeyine yükseldiği görülmüştür. Ulaşılan sonuçlar $(\overline{\mathrm{X}}=2,92)$ öğretim stratejisindeki değişiklik kararının doğruluğunu ortaya koymuştur.

\section{Yansima}

İkinci mezo döngüde öğrencilerin YNÖN geliştirme sürecindeki yansımalarına ilişkin tema, kod, frekans ve yüzdeler Tablo 6'da sunulmuştur.

Tablo 6. İkinci mezo döngüde öğrencilerin sürece yönelik yansımalarına ilişkin tema, kod, frekans ve yüzdeler

\begin{tabular}{|c|c|c|c|}
\hline Tema & Kod & Frekans & Yüzde \\
\hline \multirow{3}{*}{$\begin{array}{l}\text { YNÖN'nin öğrenmeme katkı sağlayan } \\
\text { özellikleri }\end{array}$} & İçerik miktarı & 24 & 96 \\
\hline & Etkileşim düzeyi & 22 & 88 \\
\hline & Erişim kolaylı̆̆ & 19 & 76 \\
\hline \multirow{3}{*}{$\begin{array}{l}\text { YNÖN'nin öğrenmeme katkısı } \\
\text { olmayan özellikleri }\end{array}$} & İlgililik & 11 & 44 \\
\hline & Dönüş süresi & 6 & 24 \\
\hline & Kontrol duygusu & 5 & 20 \\
\hline $\begin{array}{l}\text { YNÖN ile öğrenmemi kolaylaştıran } \\
\text { şeyler }\end{array}$ & Dijital ortamda çalışma & 25 & 100 \\
\hline \multirow[b]{2}{*}{$\begin{array}{l}\text { YNÖN ile öğrenmemi zorlaştıran } \\
\text { şeyler }\end{array}$} & İnternet kaynaklı sorunlar & 13 & 52 \\
\hline & $\begin{array}{l}\text { İşletim sistemi-yazılım } \\
\text { uyumsuzluğu kaynaklı } \\
\text { sorunlar }\end{array}$ & 15 & 60 \\
\hline Öğrenci Sayısı & & 25 & 100 \\
\hline
\end{tabular}

Tablo 6'da sunulan YNÖN geliştirme süreci yansımaları incelendiğinde, öğrencilerin \%96'sının yansımalarında YNÖN ile ilişkili içerik miktarı, \%88'inin etkileşim düzeyi ve 
\%76'sının erişim kolaylığının öğrenmelerine katkı sağladığı, herhangi bir problem yaşamadıkları ve kendilerini bu noktalarda yeterli algıladıkları görülmektedir. Öğrencilerin tamamı, YNÖN ile çalışmanın öğrenme sürecini kolaylaştırdığını, diğer yandan \%60’ı işletim sistemi-yazılım uyumsuzluğu kaynaklı sorunların öğrenme sürecini zorlaştırdığını dile getirmişlerdir.

İkinci mezo döngüde, yeniden düzenlenen ve iyileştirilen öğretim stratejisine göre, geliştirme sürecinin rubrik ve yansıma sonuçlarını destekleyici nitelikte olabilecek sürece aktif katılım sağlayan öğrencilerin geliştirme sürecine dönük olumlu ve olumsuz görüşleri ve önerileri aşağıda belirtilmiştir.

"YNÖN kullanarak oyunun yapılma aşamalarını öğrendim." (Ö1).

“Oynadığımız oyunların temelini öğrendim. Kodlar basit ve günlük hayatta duyduğumuz şeyler." (Ö2).

"Bazı püf noktalarını öğrendikten sonra uygulama yapmak kolaylaşıyor." (Ö3).

"Navigasyonda zorlandım." (Ö4).

"Kodlar basit ve günlük hayatta duyduğumuz şeyler." (Ö7).

"Diğer uygulamalara göre daha kolay." (O8).

"YNÖN ile kodlamak çok kolay." (Ö10).

"YNÖN'de yazıp kodlama sonucunda bir şeyler öğrendiğimi fark ettim." (Ö12).

“Grid koordinat sistemindeki noktaları belirlemede yardımcı oldu. Ortaya bir şeyin çıkması hoşuma gitti. Koordinat noktalarımı bulmak için yardım aldım. Kodlama sonucunda bir şeyler öğrendiğimi fark ettim." (Ö12).

"İçeriğ̊i çok iyi ve anlaşılır." (Ö13).

"Kodları şekle dönüştürmeyi iyi yaptım. Kodları yazmak daha kolay. Çünkü kod yazarken keyif aldım. Öğretmenimden yanlışlarımı düzeltmesi yönünden yardım aldım." (Ö14).

"Bilmediğim kelimeleri öğrendim, önceden bildiğim kod dili çok yardımcı oldu. Kod bilmeyen de yapabilir." (Ö15).

"Kodlardaki açıları yazarken bazen zorlandım." (Ö17).

"YNÖN arayüzü yaptığım her şeyi hemen görebilmemde bana yardımcı oldu." (Ö22).

Şekil 7'de YNÖN'ne göre geliştirilen 2. mezo döngü uygulamalarına ait örnek ekran görünümleri sunulmuştur. 


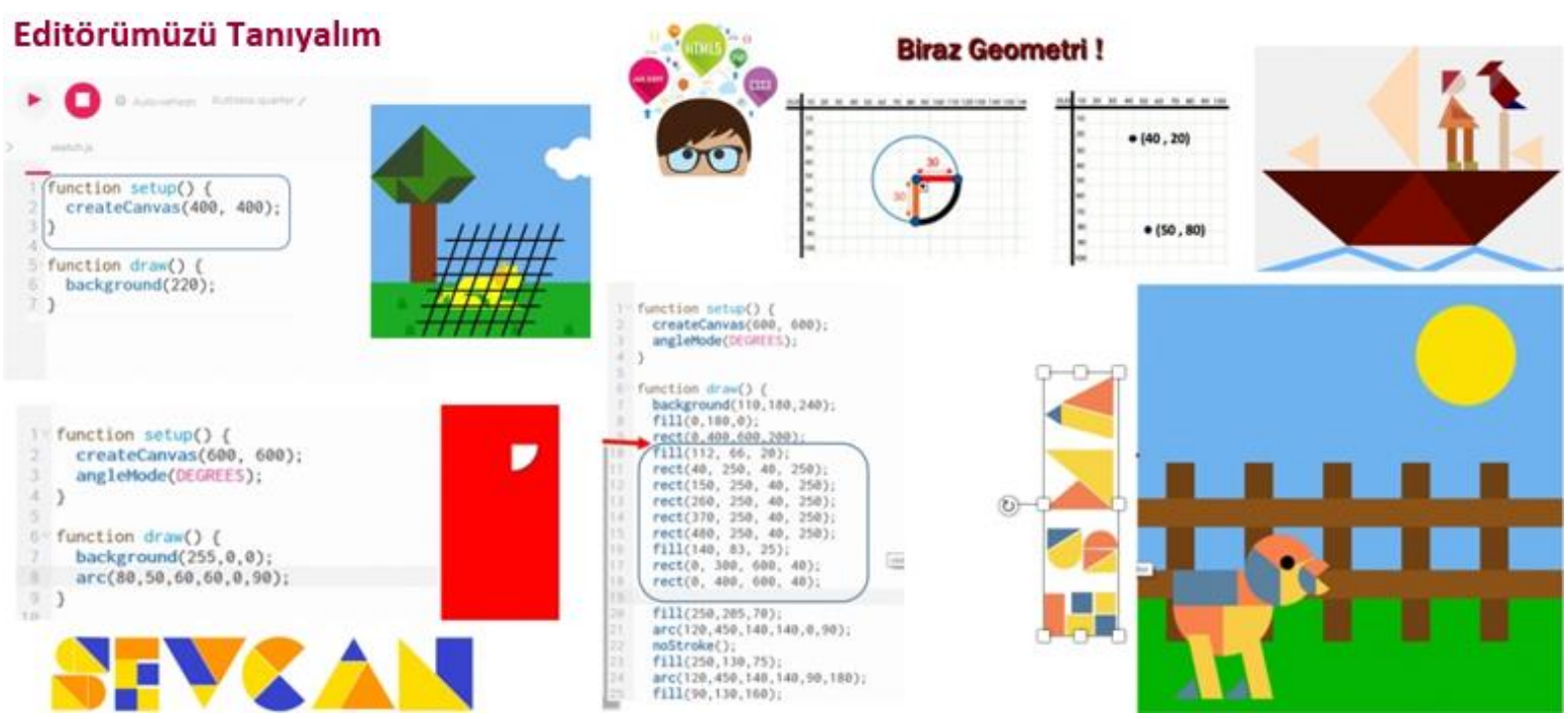

Şekil 7. İkinci mezo döngüde öğrencilerin ynön'ni deneyimleme sürecine ilişkin örnek görünümler

\section{Sonuç, Tartışma ve Öneriler}

$\mathrm{Bu}$ araştırmada öğrencilerin pedagojik, içerik ve teknik kalite algılarına göre kurgulanan YNÖN tasarlanıp, geliştirilerek değerlendirilmiştir. Araştırma, mesleki eğitim Bilişim Teknolojileri alanı 11. sınıf öğrencileriyle birbirini izleyen iki döngü şeklinde sentezlenmiş tasarım tabanlı araştırma temel alınarak modellenmiştir. Bu modelleme süreciyle, YNÖN oluşturma sürecinin tasarlanması, geliştirilmesi ve değerlendirilmesi amaçlanmıştır.

Süreç, pedagojik kalite, içerik kalitesi ve teknik kalite ölçütleri ve problem çözme alt ölçütleri kapsamında kurgulanmıştır. Öğrenme - öğretme sürecinde uygulanmak üzere geliştirilen YNÖN; (a) öğrenme kapsamı, (b) öğrenme kazanımı, (c) etkileşim seviyesi, (ç) içeriğin modülerliği, (d) algılanan öğrenme (e) dönüş süresi, (f) erişim kolaylığı̆, (g) kontrol duygusu, (h) yardım, (1) geri bildirim, (i) kayıt tutma (j) güncellik, (k) anlaşılabilirlik, (l) ilgililik, (m) uyum, (n) içerik dizilimi, (o) içerik miktarı ölçütlerine göre tasarlanması, geliştirilmesi ve değerlendirilmesi kapsamında yapılandırılmıştır.

$\mathrm{Bu}$ çalışma kapsamında, pedagojik kalite, içerik kalitesi ve teknik kalite ölçütleri temelinde kurgulanan YNÖN geliştirilmiştir. Araştırmanın her iki mezo döngüsünde de "problem analizi", “çözüm tasarlama”, “çözüm geliştirme”, “uygulamada değerlendirme” ve “yansıma” olmak üzere 5 mikro döngü bulunmaktadır. Her iki mezo döngüde elde edilen sonuçlar, öğrenme nesnesi kalite ölçütlerinin değerlendirilmelerine göre yorumlanmıştır.

Birinci mezo döngüde ulaşılan bulgular doğrultusunda ikinci mezo döngüdeki süreç yapılandırılmıştır. Her iki geliştirme sürecinde YNÖN uygulaması, sonuçları itibariyle 
öğrencilerin öğrenme nesnesi kalite algılarına göre geliştirilmiştir. YNÖN geliştirme sürecinde her iki mezo döngüdeki ÖNKR sonuçları incelendiğinde, pedagojik kalite, içerik kalitesi ve teknik kalite ölçütlerinde 2. mezo döngüde dikkat çeken bir yükseliş olduğunu söylemek mümkündür (Şekil 8). Bir öğretim materyalinden öğretim programıyla uyumlu, içeriğin doğru ve güncel, dilinin sade ve anlaşılır olması, öğrenciyi güdüleyici ve ilgiyi sürekli tutacak özelliklere sahip olması ve teknik açıdan yeterli olması beklenmektedir (Seferoğlu, 2009).

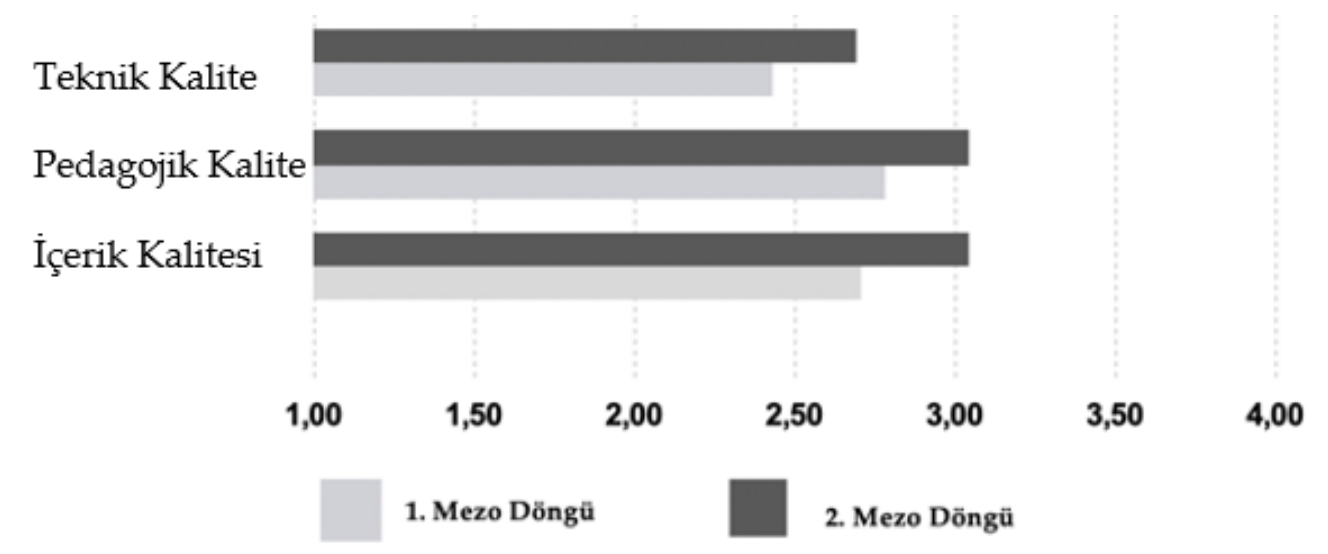

Şekil 8. Birinci ve ikinci mezo döngülerde elde edilen ÖNKR sonuçlarının karşılaştırılması

Birinci mezo döngüde öğrencilerin tangram processing kodlarını kendileri yazarken zorluk yaşadıkları ve sıkıldıkları görülmüştür. Bu doğrultuda 2. mezo döngüde pedagojik ve içerik kalitesinde düzenlemelere gidilmiştir. Ögrencilere hazır processing kod paketleri verilmiş ve tangrama ek olarak isimlerini yazmaları istenmiştir. Sonuç olarak ikinci döngüdeki YNÖN değerlendirme ortalamaları ve öğrenci görüşleri doğrultusunda YNÖN'nin bu hâliyle etkili bir öğrenme materyali olarak kullanılabileceği görülmektedir.

Araştırma kapsamında YNÖN tasarlanmış, geliştirilmiş ve değerlendirilmiştir. Gelecek çalışmalarda öğrenme-öğretme sürecinde YNÖN geliştirme süreci, bilişsel yük kuramına göre kurgulanarak etkisi incelenebilir. Ayrıca araştırmadaki iki döngü, öğrenme nesnesi kavramıyla ilk kez karşılaşan öğretmen ve öğrencilerle gerçekleştirilmiş, YNÖN'nin hazırlanması sürecinin önemli bir kısmını oluşturmuştur. İleriki çalışmalarda YNÖN geliştirme süreciyle ilgili deneyim kazanmış öğretmen ve öğrencilerle bu model yeniden düzenlenebilir. Farklı dersler ve farklı kazanımlara yönelik olarak başka sentezlenmiş tasarım tabanlı araştırmalar yürütülebilir. 
Bilgilendirme

Bu çalışma, ikinci yazarın birinci yazar danışmanlı̆̆ında tamamlamış olduğu yüksek lisans tezinden üretilmiştir.

Bu çalışmada kullanılan verilerin 2020 yılı öncesine ait olduğu araştırmacılar tarafından onaylanmıştır.

Yazar Katkı Beyanı

G. Alev ÖZKÖK: Kavramsallaştırma, yöntem, danışmanlık ve denetim (ölçme aracı, veri analizi, döngülerin tasarımı), inceleme-yazma, düzenleme ve kontrol

Tuğçe YILMAZ: Kavramsallaştırma, veri toplama, ön yazım ve düzenleme, kontrol ve son okuma

\section{Kaynaklar}

ADL, SCORM ${ }^{\circledR}$ 2004. 4th edition content aggregation model (CAM) Version 1.1. http://www.adlnet.gov/research/scorm/scorm-2004-4th-edition

Baki, A., \& Çakıroğlu, Ü. (2010). Learning objects in high school mathematics classrooms: Implementation and evaluation. Computers $\mathcal{E}$ Education, 55(4), 1459-1469.

Barak, M., \& Ziv, S. (2013). Wandering: A web-based platform for the creation of locationbased interactive learning objects. Computers \& Education, 62, 159-170.

Barritt, C., \& Alderman Jr., F. L. (2004). Creating a reusable learning objects strategy: Leveraging information and learning in a knowledge economy. San Francisco: John Wiley \& Sons, Inc.

Baruque, L., \& Melo, R. (2004). Learning theory and instructional design using learning objects. Journal of Educational Multimedia and Hypermedia, 13(4), 343-370.

Becerra, C., Astudillo, H., \& Mendoza, M. (2012). Improving learning objects recommendation processes by using domain description models. 7th Latin American Conference on Learning Objects and Educational Technologies (LACLO 2012).

Boyle, T. (2009). Generative learning objects (GLOs): Design as the basis for reuse and repurposing. In 1st International Conference on e-Learning and Distance Learning, Riyadh, Saudi Arabia, March 16- 182009 (pp. 1-22).

Burbaite, R., Bespalova, K., Damasevicius, R., \& Stuikys, V. (2014). Context aware generative learning objects for teaching computer science. International Journal of Engineering Education, 30(4), 929-936.

Chapuis, L. (2003). Report on a pedagogical trial of learning objects in ACT schools. Griffith: Centre for Teaching and Learning Technologies.

Di Nitto, E., Mainetti, L., Monga, M., Sbattella, L., \& Tedesco, R. (2006). Supporting interoperability and reusability of learning objects: The virtual campus approach. Educational Technology \& Society, 9(2), 33-50.

Friesen, N. (2001). What are educational objects? Interactive Learning Environments, 9(3), 219230. doi: 10.1076/ilee.9.3.219.3573

Gordillo, A., Barra, E., \& Quemada, J. (2017). An easy to use open source authoring tool to create effective and reusable learning objects. Computer Applications in Engineering Education, 25(2), 188-199. doi: 10.1002/cae.21789 
Hodgins, H.W. (2002). The future of learning objects. In D.A. Wiley (Ed.). The instructional use of learning objects. Bloomington, IN: Association for Educational Communications and Technology. Available online at http://reusability.org/read/.

IEEE Learning Technology Standards Committee (2002). Learning object metadata standard. IEEE 1484.12.1. http://1tsc.ieee.org/wg12/

IMS (Instructional Management Systems) (2004). IMS content packaging best practice and implementation guide Version 1.1.4. www.imsglobal.org/

Kay, R. H., \& Knaack, L. (2008). A formative analysis of individual differences in the effectiveness of learning objects in secondary school. Computers $\mathcal{E}$ Education, 51(3), 1304-1320. doi: 10.1016/j.compedu.2008.01.001

Kurilovas, E., Kubilinskiene, S., \& Dagiene, V. (2014). Web 3.0-Based personalisation of learning objects in virtual learning environments. Computers in Human Behavior, 30, 654662. doi: 10.1016/j.chb.2013.07.039

Lau, S. H., \& Woods P. C. (2008). An investigation of user perceptions and attitudes toward learning objects. British Journal of Educational Technology, 39(4), 685-699.

Lau, S. H., \& Woods P. C. (2009a). Understanding the behavior changes in belief and attitude among experienced and inexperienced learning object users. Computers $\mathcal{E}$ Education, 52(2), 333-342. doi: 10.1016/j.compedu.2008.09.002

Lau, S. H., \& Woods P. C. (2009b). Understanding learner acceptance of learning objects: The roles of learning object characteristics and individual differences. British Journal of Educational Technology, 40(6), 1059-1075. doi: 10.1111/j.1467-8535.2008.00893.x

Li, Y., \& Li, M. (2014). Learning objects automatic generation system for multiple data formats. Proceedings of the 3rd International Conference on Computer Science and Service System (CSSS 2014), 203-206. doi: 10.2991/csss-14.2014.47

Mavrommatis, G. (2008). Learning objects and objectives towards automatic learning construction. European Journal of Operational Research, 187(3), 1449-1458.

McGee, P. (2003). Learning objects: Bloom's taxonomy and deeper learning principles. Accepted for presentation at the E-Learn Conference, Phoenix, AZ (7-11 Nov). 6 Haziran 2020 tarihinde https://studylib.net/doc/7468801/learning-objects--bloom-s-taxonomy-and-deeperlearning-pr... adresinden erişildi.

McKenney, S., \& Reeves, T. C. (2012). Conducting educational design research. London: Routledge.

MEB (2018). 2023 eğitim vizyonu. Milli Eğitim Bakanlı̆̆1. http://2023vizyonu.meb.gov.tr/doc/2023_EGITIM_VIZYONU.pdf adresinden erişilmiştir.

Nesbit, J. C., Belfer, K., \& Leaclock, T. (2003). Learning object review instrument (LORI)

http://www.elera.net

Northrup, P. (2007). Learning objects for instruction: Design and evaluation. London, England: Information Science Publishing.

Özkök, G. A., \& Akpolat, M. E. (2020). Üniversite öğrencilerinin öğrenme nesneleri kullanımlarının öğrenme nesnesi kabul modeline göre incelenmesi. Hacettepe Üniversitesi Eğitim Fakültesi Dergisi. Advance online publication. doi: 10.16986/HUJE.2020062665.

Özkök, G. A. (2015). Yaratıcı problem çözme metodu ile öğrenme nesnesi tasarımı ve geliştirilmesi. B. Akkoyunlu, A. \& H. F. Odabaşı (Ed.). Eğitim Teknolojileri Okumaları 2015. (s. 421 - 446). TOJET - Sakarya Üniversitesi. 
Polsani, P. R. (2003). Use and abuse of reusable learning objects. Journal of Digital Information, 3(4). https://journals.tdl.org/jodi/index.php/jodi/article/view/89/88 adresinden 10.07.2020 tarihinde erişilmiştir.

Queiros, L. M., da Silveira, D. S., da Silva Correia-Neto, J., \& Vilar, G. (2016). LODPRO: Learning objects development process. Journal of the Brazilian Computer Society, 22(1), 19. doi: 10.1186/s13173-016-0043-6

Ritzhaupt, A. (2010). Learning object systems and strategy: A description and discussion. Interdisciplinary Journal of e-learning and Learning Objects, 6(1), 217-238.

Saldana Hernandez, K. A., Hernández Velázquez, Y., López Domínguez, E., Excelente Toledo, C. B., \& Medina Nieto, M. A. (2018). MOAM: A methodology for developing mobile learning objects (MLOs). Computer Applications in Engineering Education, 26(1), 17-28. Doi: 10.1002/cae.21857

Saum, R. R. (2007). An abridged history of learning objects. In Learning objects for instruction: Design and evaluation (pp. 1-15). IGI Global.

Silveira, R. A., \& da Silva, J. M. C. (2008). Building intelligent learning environments using intelligent learning objects. In Agent-Based Tutoring Systems by Cognitive and Affective Modeling (pp. 19-42). IGI Global.

Slotkienė, A., Baniulis, K. T., \& Paulikas, G. (2009). Desining reusable active learning object by using its information model. Jaunuju mokslininku darbai, 3(24), 107-113.

Štuikys, V., Burbaite, R., \& Damaševicius, R. (2013). Teaching of computer science topics using meta-programming-based GLOs and LEGO robots. Informatics in Education, 12(1), 125-142.

Štuikys, V. (2015). Model-driven specification in designing smart LOs. In Smart Learning Objects for Smart Education in Computer Science (pp. 103-122). Springer, Cham. doi: 10.1007/978-3-319-16913-2_5

Taamallah, A., \& Khemaja, M. (2014). Designing and experiencing smart objects based learning scenarios: an approach combining IMS LD, XAPI and IoT. In Proceedings of the 2nd International Conference on Technological Ecosystems for Enhancing Multiculturality (pp. 373-379). ACM. doi: 10.1145/2669711.2669926

Wang, J., Mendori, T., \& Hoel, T. (2019). Strategies for multimedia learning object recommendation in a language learning support system: Verbal learners vs. visual learners. International Journal of Human-Computer Interaction, 35(4-5), 345-355.

Wiley, D. A. (2000). Learning object design and sequencing theory. (Unpublished doctoral dissertation), Brigham Young University, Provo, UT.

Van Wyk, E., \& De Villiers, M. (2014). Applying design-based research for developing virtual reality training in the south african mining industry. Paper presented at the Proceedings of the Southern African Institute for Computer Scientist and Information Technologists Annual Conference 2014 Empowered by Technology (pp.70-81). doi: 10.1145/2664591.2664627

Yıldırım, A., \& Şimşek, H. (2013). Sosyal bilimlerde nitel araştırma yöntemleri (9. Baskı). Ankara: Seçkin Yayıncılık.

Copyright $\odot$ JCER

JCER's Publication Ethics and Publication Malpractice Statement are based, in large part, on the guidelines and standards developed by the Committee on Publication Ethics (COPE). This article is available under Creative Commons CC-BY 4.0 license (https://creativecommons.org/licenses/by/4.0/) 